Fossill Energy Program ANL/FE-97/01

Fossil Energy Program Fossil Energy Program Fossil Energy Program Fossil Energy Program Fossil Energy Program Fossil Energy Program Fossil Energy Program Fossil Energy Program Fossil Energy Program Fossil Energy Program Fossil Energy Program Fossil Energy Program Fossil Energy Program Fossil Energy Program Fossil Energy Program Fossil Energy Program Fossil Energy Program Fossil Energy Program Fossil Energy Program Fossil Energy Program Fossil Energy Program Fossil Energy Program Fossil Energy Program Fossil Energy Program Fossil Energy Program Fossil Energy Program Fossill Energy Program Fossil Energy Program Fossil Energy Program Fossil Energy Program

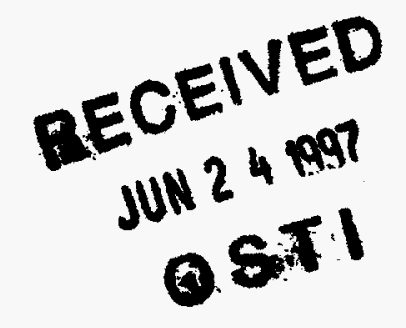

\title{
Fracture Behavior of Advanced Ceramic Hot Gas Filters: Final Report
}

by J. P. Singh, S. Majumdar,
M. Sutaria, and W. Bielke

Report Prepared by Argonne National Laboratory 9700 South Cass Avenue Argonne, Illinois 60439 under Subcontract Number 10X-SS107V

for

Oak Ridge National Laboratory Oak Ridge, Tennessee 37831

Managed by

Martin Marietta Energy Systems, Inc. for the U.S. Department of Energy under Contract No. DE-AC05-960R22464

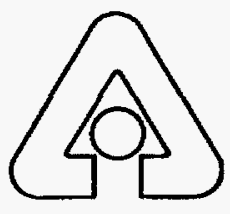

Argonne National Laboratory, Argonne, Illinois 60439

operated by The University of Chicago

for the United States Department of Energy under Contract W-31-109-Eng-38

Energy Technology

Division

Energy Technology

Division

Energy Technology

Division

Energy Technology

MASTER

HH 
This report has been reproduced directly from the best available copy.

Available to DOE and DOE contractors from the Office of Scientific and Technical Information, P.O. Box 62, Oak Ridge, TN 37831 ; prices available from (423) 576-8401.

Available to the public from the National Technical Information Service, U.S. Department of Commerce, 5285 Port Royal Rd., Springfield, VA 22161.

This report was prepared as an account of work sponsored by an agency of the United States Government. Neither the United States Government nor any agency thereof, nor any of their employees, makes any warranty, expressed or implied, or assumes any legal liability or responsibility for the accuracy, completeness, or usefulness of any information, apparatus, product, or process disclosed, or represents that its use would not infringe privately owned rights. Reference herein to any specific commercial product, process, or service by trade name, trademark, manufacturer, or otherwise, does not necessarily constitute or imply its endorsement, recommendation, or favoring by the United States Government or any agency thereof. The views and opinions of authors expressed herein do not necessarily state or reflect those of the United States Government or any agency thereof. 
ANL/FE-97-01

FRACTURE BEHAVIOR OF ADVANCED CERAMIC HOT GAS FIITERS:

FINAL REPORT

by

J. P. Singh, S. Majumdar, M. Sutaria, and W. Bielke

Energy Technology Division

March 1997

Research sponsored by the U.S. Department of Energy,

Office of Fossil Energy

Advanced Research and Technology Development Materials Program

Report Prepared by

Argonne National Laboratory

9700 South Cass Avenue

Argonne, Illinois 60439

under

Subcontract Number 10X-SS107V

for

OAK RIDGE NATIONAL LABORATORY

Oak Ridge, Tennessee 37831

Managed by

MARTIN MARIETTA ENERGY SYSTEMS, INC.

for the

U.S. Department of Energy

under Contract No. DE-AC05-960R22464 



\section{DISCLAIMER}

This report was prepared as an account of work sponsored by an agency of the United States Government. Neither the United States Government nor any agency thereof, nor any of their employees, make any warranty, express or implied, or assumes any legal liability or responsibility for the accuracy, completeness, or usefulness of any information, apparatus, product, or process disclosed, or represents that its use would not infringe privately owned rights. Reference herein to any specific commercial product, process, or service by trade name, trademark, manufacturer, or otherwise does not necessarily constitute or imply its endorsement, recommendation, or favoring by the United States Government or any agency thereof. The views and opinions of authors expressed herein do not necessarily state or reflect those of the United States Government or any agency thereof. 


\section{DISCLAIMER}

Portions of this document may be illegible in electronic image products. Images are produced from the best available original docoment. 


\section{CONTENTS}

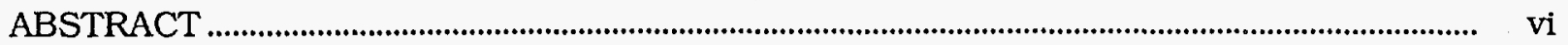

$1 \quad$ INTRODUCTION

2 SPECIMENS FOR FRACTURE STUDIES ...................................................................

3 EVALUATION OF STRENGTH AND THERMAL SHOCK RESISTANCE ........................... 2

3.1 O-Ring Compression Test .............................................................................................. 2

3.2 In-Situ Fiber Strength Evaluation .............................................................................. 4

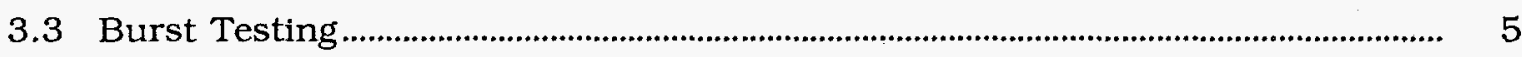

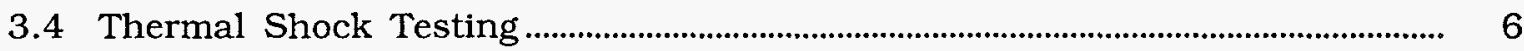

$4 \quad$ EVALUATION OF THERMAL FATIGUE BEHAVIOR ............................................................... 8

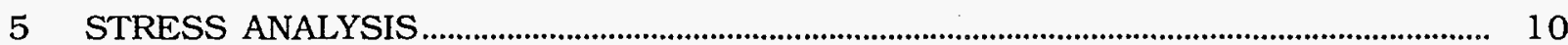

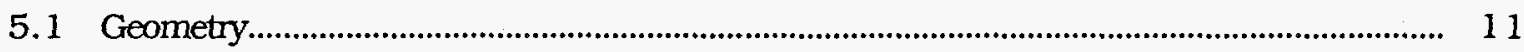

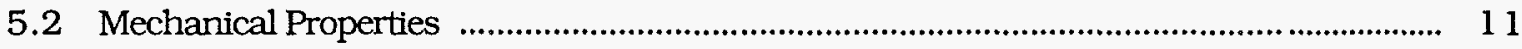

5.2.1 Axial Tensile Testing of Composite without Filter Element................. 11

5.2.2 Burst Testing with an Internal Plug ................................................................. 14

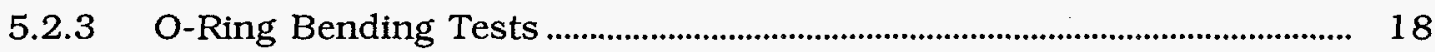

5.2.3.1 O-Ring Bending Test of Composite without Filter Element.. 19

5.2.3.2 O-Ring Bending Test of Composite with a Filter Element..... 22

5.3 Thermal-Shock Effects …........................................................................................... 23

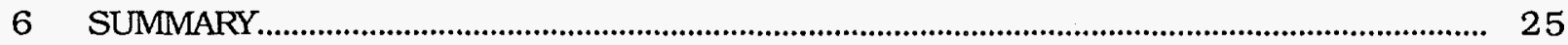

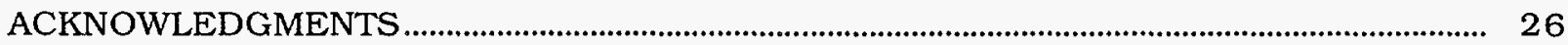

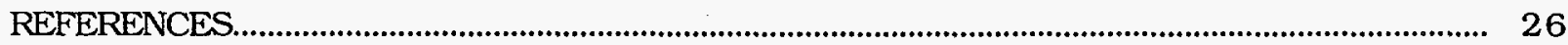

APPENDIX A: Determination of Membrane and Bending Stiffnesses of Composite........ 27

APPENDIX B: Effects of Friction on Burst Tests with Internal Plug ....................................... 35 


\section{FIGURES}

1 Typical load-displacement plots for Nextel ${ }^{\mathrm{TM}} / \mathrm{SiC}$ and $\mathrm{SiC}$ filters, indicating nonbrittle and brittle fractures

2 Photomicrograph of fracture surface of Nextel ${ }^{\mathrm{TM}} / \mathrm{SiC}$ and $\mathrm{SiC}$ filters, showing nonbrittle and brittle fractures

3 Weibull strength distribution of Nextel ${ }^{\mathrm{TM}}$ fibers in Nextel ${ }^{\mathrm{TM}}$ fibers/SiC composite filters in as-fabricated and exposed conditions

4 Schematic diagram of burst test setup .....................................................................................

5 Typical load-displacement plot for Nextel ${ }^{\mathrm{TM}} / \mathrm{SiC}$ filter specimens .............................. 5

6 Schematic diagram of thermal quench test apparatus......................................................

7 Dependence of retained strength of ring specimens on quenching temperature difference.

8 Dependence of area under load-displacement curve for Nextel ${ }^{\mathrm{TM}} / \mathrm{SiC}$ ring specimens on quenching temperature difference.

9 Photomicrograph of fracture surface of Nextel ${ }^{\mathrm{TM}} / \mathrm{SiC}$ ring specimens ........................ 9

10 Dependence of retained strength on number of thermal cycles............................... 10

11 Typical setup for O-ring bending test, and typical burst test setup for $3 \mathrm{M}$ filter with use of internal rubber plug.

12 Assumed distribution of fibers in a single tow...................................................................... 13

13 Geometry and representative volume element of 3M woven composite.................... 13

14 Predicted vs. observed load-displacement diagram for axial tensile test on composite cylinder (without filter)....

15 Calculated vs. experimentally measured load-displacement curves of plug for composite (with filter element)

16 Calculated vs. experimentally measured load-displacement curves of plug for composite (without filter element)

17 Variations of fraction of matrix thickness that cracked, composite bending stiffness, and maximum fiber stress with applied bending moment when longitudinal shear and interlaminar bonds between tows are undamaged and broken

18 Predicted vs. observed load-displacement curve for O-ring test on composite cylinder

19 Variation of maximum fiber stress with bending moment at a section, for various assumptions in model. 
20 Typical load-displacement diagram for O-ring bending test on as-received filter and filter subjected to thermal shock quenching temperature of $1100^{\circ} \mathrm{C}$

21 Calculated variations of displacement and maximum interfacial shear stress and maximum stresses in fiber and matrix with load for composite with filter element

22 Variation of maximum stresses in fiber and matrix as functions of quenching temperature for composite with filter element

TABLE

1 Mechanical properties of constituents of $3 \mathrm{M}$ filter used in model calculations. 


\title{
FRACTURE BEHAVIOR OF ADVANCED CERAMIC HOT GAS FILTERS:
}

FINAL REPORT

J. P. Singh, S. Majumdar, M. Sutaria, and W. Bielke

\begin{abstract}
This report presents the results of mechanical/microstructural evaluation, thermal shock/fatigue testing, and stress analyses of advanced hot-gas filters obtained from different manufacturers. These filters were fabricated from both monolithic ceramics and composites. The composite filters, made of both oxide and nonoxide materials, were in both as-fabricated and exposed conditions, whereas the monolithic filters were made only of nonoxide materials. Mechanical property measurement of composite filters included diametral compression testing with O-ring specimens and burst-testing of short filter segments with rubber plugs. In-situ strength of fibers in the composite filters was evaluated by microscopic technique. Thermal shock/fatigue resistance was estimated by measuring the strengths of filter specimens before and after thermal cycling from an air environment at elevated temperatures to a room temperature oil bath. Filter performance during mechanical and thermal shock/fatigue loadings was correlated with microstructural observations. Micromechanical models were developed to derive properties of composite filter constituents on the basis of measured mechanical properties of the filters. Subsequently, these properties were used to analytically predict the performance of composite filters during thermal shock loading.
\end{abstract}

Research sponsored by the U.S. Department of Energy, Fossil Energy Advanced Research and Technology Development Materials Program, DOE/FE AA 151010 0, Work Breakdown Structure Element ANL-1(A). 


\section{INTRODUCTION}

Hot, dirty gas exiting from a gasifier or an advanced combustor contains sufficient particulates to warrant it undesirable for direct utilization in gas turbines and heat engines. Today's hot, dirty gas cleanup systems, such as cyclones, can remove only the fraction containing larger-size particulates. Smaller particulates can be removed only by cooling and filtering the gas. The resulting enthalpy loss causes a significant decrease in overall system efficiency. Thus, there is a critical need for cleaning hot dirty gas with little or no cooling. The U.S. Department of Energy and others are currently supporting the development of ceramic/composite filter technology for combined-cycle power generation with coal gasification. Ceramic filter should essentially remove all of the fines from a hot-dirty gas stream and be stable in hot-dirty gas environments.

This project supports the development of candle ceramic/composite filters for cleanup of hot, dirty gases. Effort has been directed toward developing materials qualification technology needed to ensure satisfactory performance of filters in hot, dirty gas stream. In order to predict long-term performance of the ceramic/composite hot-gas filters, it is important to understand and evaluate fracture behavior of these filters in service environments. Mechanical properties should be evaluated to establish baseline data. Thermal shock resistance should be measured to predict filter failure in service environment [1]. Failure modes must be identified and failure mechanisms must be established. Stress analyses should be performed and model should be developed to predict filter performance.

In this report, the results will be presented on mechanical/microstructural evaluations and stress analyses for the filters obtained from the 3M, Du Pont Lanxide, Industrial Filter and Pump Mfg Co. (IFPM), Pall Corp., and Babcock \& Wilcox. Specifically, presented are the experimental results on the strength, thermal shock resistance, and microstructure and the analytical results of micromechanical modeling to predict stress-strain behavior of composite filters during mechanical and thermal shock loadings for the filters.

\section{SPECIMENS FOR FRACTURE STUDIES}

Filters studied were obtained from 3M (Nextel ${ }^{\mathrm{TM}} / \mathrm{SiC}$ composite filters), Du Pont Lanxide (PRD-66 filters), Babcock \& Wilcox (oxide composites), Industrial Filter and Pump Mfg Co. (IFPM) (monolithic SiC and Recrystallized SiC filters), and Pall Corp. (monolithic $\mathrm{SiC}$. The $3 \mathrm{M}$ filters consist of layered composite structures. A tubular filter element is sandwiched between the two Nextel ${ }^{\mathrm{TM}} / \mathrm{SiC}$ composite tubes. The bonding between the NextelTM/SiC composite tubes and the filter layer is achieved by the chemical vapor infiltration (CVI) of SiC. The inner and outer diameters of these filters are $\approx 5.08 \mathrm{~cm}$ and $\approx 5.72 \mathrm{~cm}$, respectively. Filters were obtained in both as-fabricated and exposed (in the Tidd demonstration plant for $\approx 1100 \mathrm{~h}$ ) conditions. The PRD-66 is an all-oxide ceramic consisting of layered microstructure of alumina, mullite, cordierite, and some amorphous material. The inner and outer diameters of the filters are $\approx 4.52$ and $\approx 5.96 \mathrm{~cm}$, respectively. The Babcock \& Wilcox filter is made of an oxide composite with chopped and continuous Nextel fibers using a sol-gel technique. The inner and outer diameters of the filters are $\approx 5.00$ and $\approx 5.96 \mathrm{~cm}$, respectively. Both monolithic SiC filters primarily consists of $\mathrm{SiC}$ grains. The inner and outer diameters of the filters are $\approx 4.52$ and $\approx 5.96 \mathrm{~cm}$, respectively. 


\section{EVALUATION OF STRENGTH AND THERMAL-SHOCK RESISTANCE}

Strength of candle filters was evaluated by both diametral compression testing of O-ring specimens and by burst testing of short filter segments with rubber plugs.

\subsection{O-RING COMPRESSION TEST}

One-inch-wide O-ring specimens were machined from each of the filters. These specimens were loaded to failure in a diametral compression mode at a crosshead speed of $0.13 \mathrm{~cm} / \mathrm{min}$. The maximum stress in a homogeneous cylinder develops at the inner diameter across the load points, which simulates the thermal-shock stresses developed during the pulse-cleaning cycle. The fracture stress, $\sigma_{\mathrm{f}}$ is given by [2]

$$
\sigma_{f}=\frac{\mathrm{PK}}{\pi \mathrm{bl} l}
$$

where $\mathrm{P}$ is the fracture load, $\mathrm{K}$ is a function of the ratio of inner and outer diameters [2], $\mathrm{b}$ is the outer radius of the specimen, and $l$ is the length of the tube. This equation is applicable for a homogeneous cylinder. For layered composite cylinders, it provides only a relative load-carrying capability under different processing and service conditions. A detailed analysis is provided in the Stress Analysis Section of this report. The loaddisplacement plots for the filter specimens in as-fabricated condition indicated a nonbrittle failure mode for all composites, while the monolithic filters showed brittle failure (e.g., Fig. 1).

The load-displacement plots in Fig. 1 are consistent with the observed microstructure on the fracture surfaces of these filter specimens. Figure 2 shows photomicrographs of the fracture surfaces of Nextel $\mathrm{TM}_{\mathrm{TM}} \mathrm{SiC}$ and monolithic SiC filters. Clearly visible is a substantial amount of fiber pullout in the composite filter, resulting in a nonbrittle failure mode. On the other hand, the photomicrograph for the monolithic filters shows a brittle fracture that is consistent with the load-displacement plot.

O-ring compression tests conducted on NextelTM/SiC samples machined from composite hot-gas filters in as-fabricated condition showed an ultimate strength of $19.7 \pm 2$ $\mathrm{MPa}$. The corresponding value of ultimate strength for filters exposed in the Tidd demonstration plant for $\approx 1100 \mathrm{~h}$ was $7.7 \pm 1 \mathrm{MPa}$. This represents a strength loss of $\approx 60 \%$ during filter
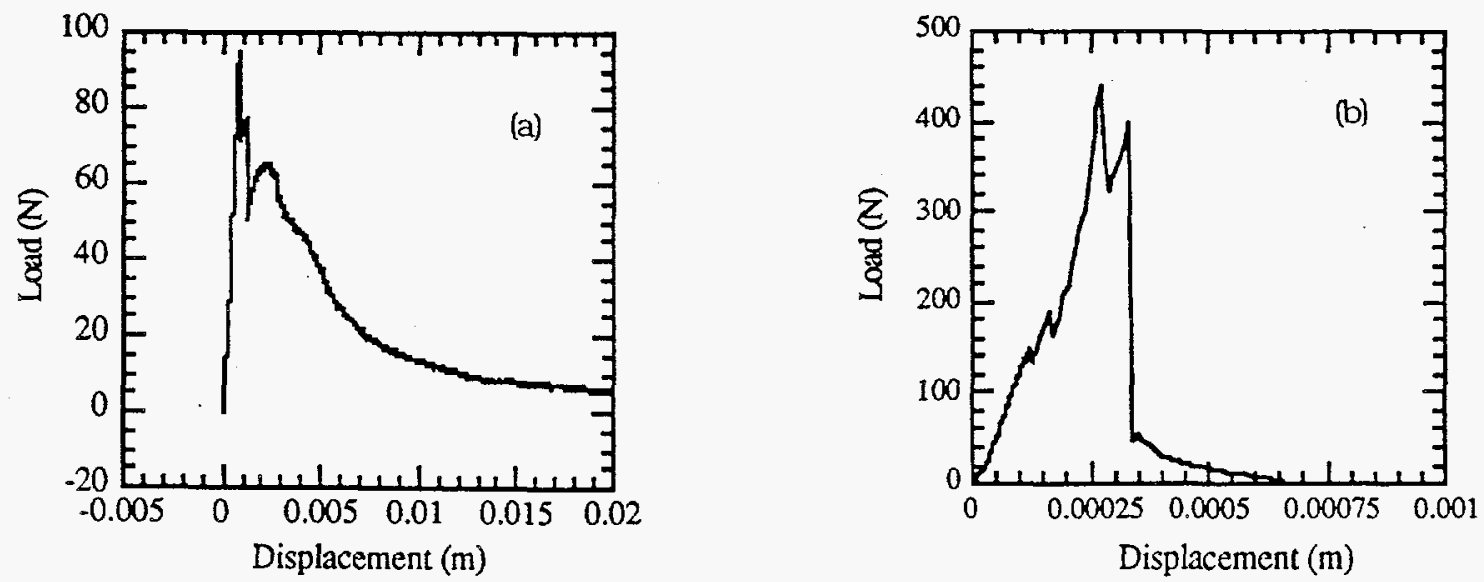

Fig. 1. Typical load-displacement plots for (a) Nextel ${ }^{\mathrm{TM}} / \mathrm{SiC}$ and (b) SiC filters, indicating nonbrittle and brittle fractures. 

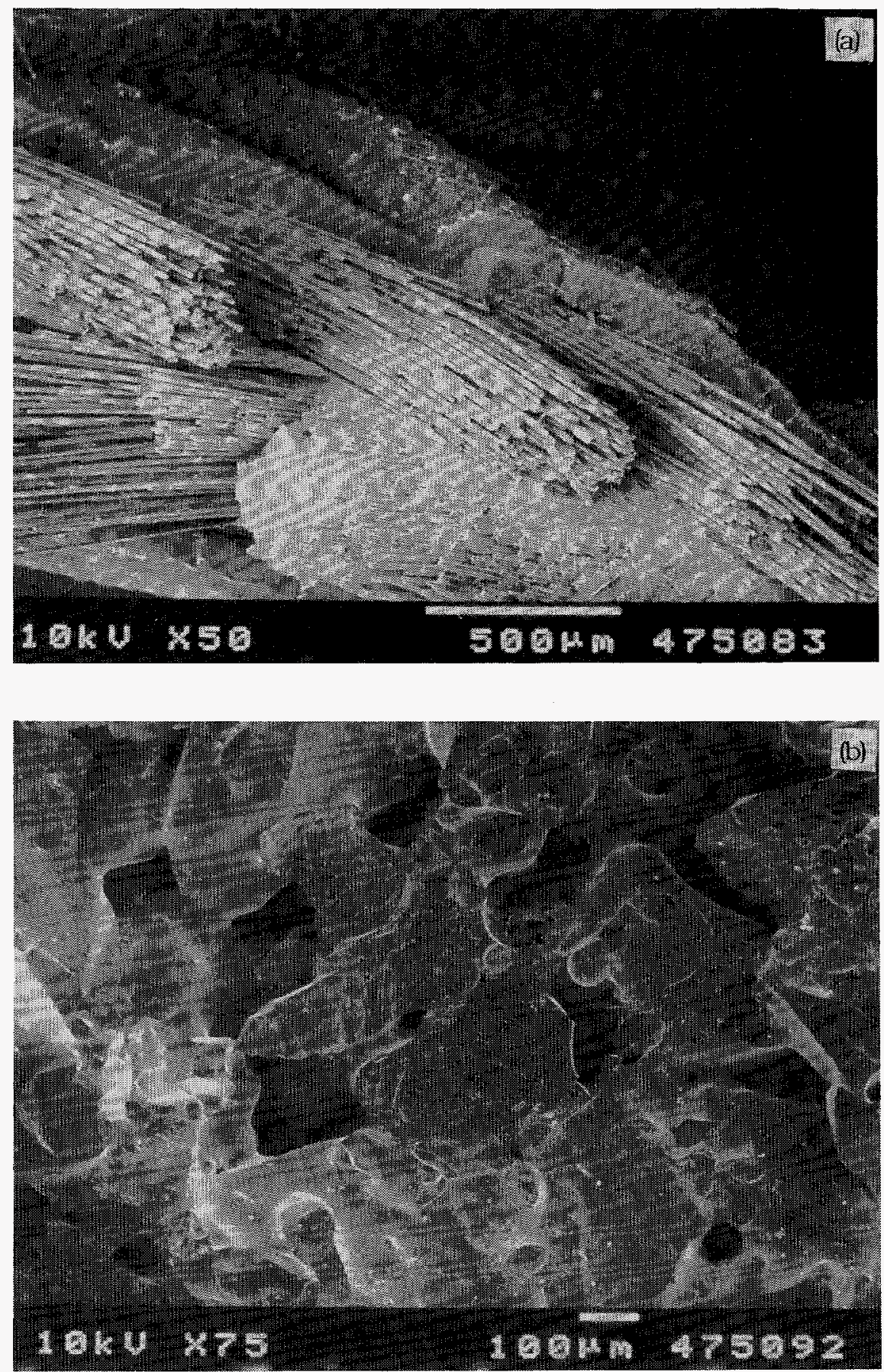

Fig. 2. Photomicrograph of fracture surface of (a) Nextel ${ }^{\mathrm{TM}} / \mathrm{SiC}$ and (b) SiC filters, showing nonbrittle and brittle fractures.

exposure. Based on the observation in other studies [3,4], we believe that the degradation in the ultimate strength of composite filters is related to the degradation of in-situ fiber strength. Therefore, we evaluated the in-situ strength of reinforcing fibers in as-fabricated and exposed filters using the fractographic technique. 


\subsection{IN-SITU FIBER STRENGTH EVALUATION}

In-situ strength of fibers in the Nextel TM/SiC composite filters in unexposed and exposed conditions was evaluated from characteristic fracture features of the fibers. Strength of fractured fibers were determined from the measured values of fracture mirror radii, as discussed in regard to use of the empirical relationship proposed by Kirchner and Gruver [5] and as given in

$$
\sigma_{\mathrm{f}} \sqrt{\mathrm{r}_{\mathrm{m}}}=\mathrm{A}_{\mathrm{m}} \text {, }
$$

where $\sigma_{\mathrm{f}}$ is the fiber fracture strength, $\mathrm{r}_{\mathrm{m}}$ is the measured fiber mirror radius, and $\mathrm{A}_{\mathrm{m}}$ is the mirror constant and is taken to be $3.5 \mathrm{MPa} \vee \mathrm{m}$.

The measured values of in-situ fiber strengths were described by the Weibull strength distribution function, as shown in Eq. 3.

$$
\mathrm{F}(\sigma)=1-\exp \left[-\frac{\mathrm{L}}{\mathrm{L}_{\mathrm{o}}}\left(\frac{\sigma}{\sigma_{o}}\right)^{\mathrm{m}}\right],
$$

where $F(\sigma)$ is the cumulative failure probability at an applied stress $\sigma, L_{O}$ is the fiber gage length at which Weibull parameters are estimated, $\mathrm{L}$ is the standard gage length taken to be $10 \mathrm{~mm}, \sigma_{o}$ is the scale parameter signifying a characteristic strength of the distribution, and $\mathrm{m}$ is the Weibull modulus that characterizes the flaw distribution in the material.

A very limited number of developmental filters have been tested in actual pilot plants. Therefore, the willingness of $3 \mathrm{M}$ to provide one of the tested filters (which are in high demand) for our evaluation is greatly appreciated. Figure 3 shows the distribution of insitu strengths of the fibers in composite filters in both unexposed and exposed conditions.

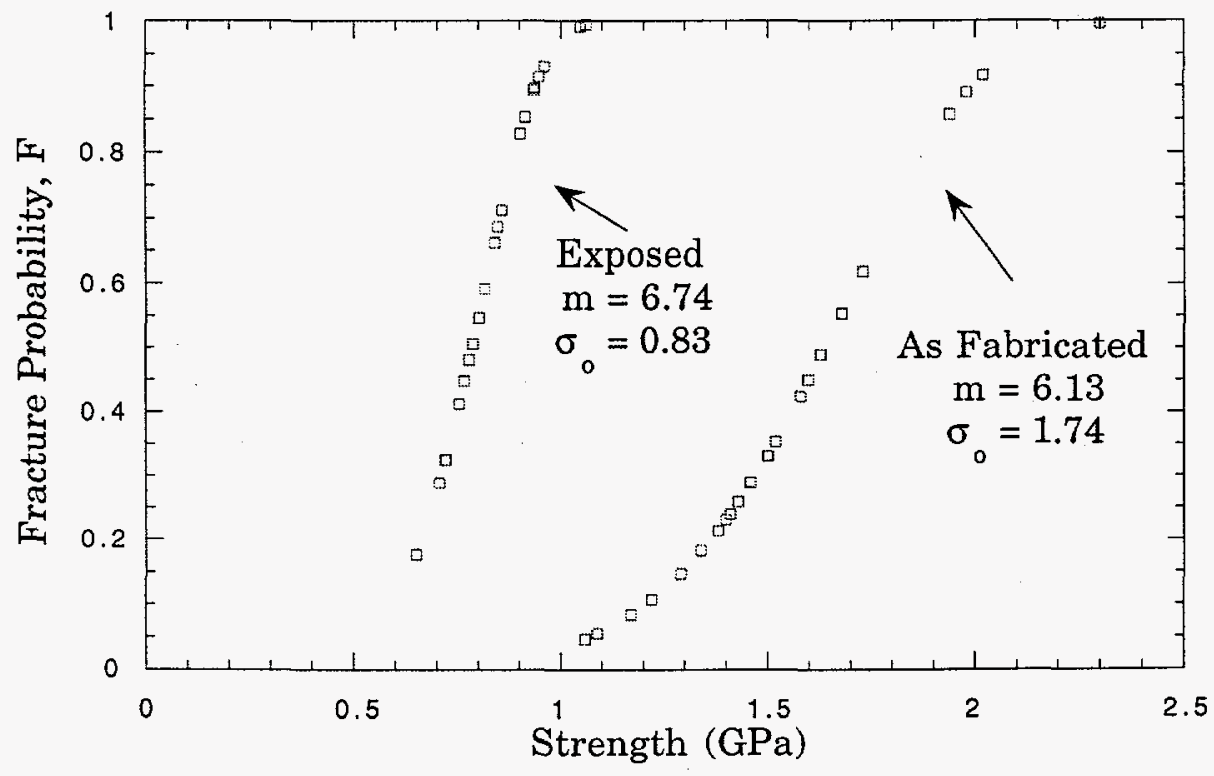

Fig. 3. Weibull strength distribution of Nextel ${ }^{T M}$ fibers in Nextel ${ }^{T M}$ fibers/SiC composite filters in as-fabricated and exposed conditions. 
The average value of fiber strength in unexposed filter is $1.74 \mathrm{GPa}$, while average in-situ strength of fibers in exposed composite filter is $0.83 \mathrm{GPa}$. Thus, degradation of in-situ strength of fiber during exposure is $\approx 52 \%$, in agreement with the strength degradation of filters. This confirms that filter strength degradation is related to fiber damage.

\subsection{BURST TESTING}

Burst testing was performed on 1-in.-wide-O-ring specimens machined from NextelTM/SiC composite filters in as-fabricated condition. As shown in Fig. 4, load was applied to the O-rings through a rubber plug (1.94 in. in diameter and $1.5 \mathrm{in}$. long), which was compressed between two aluminum plates. Figure 5 shows a typical load-displacement plot for a NextelTM/SiC composite filter specimen in as-fabricated condition.

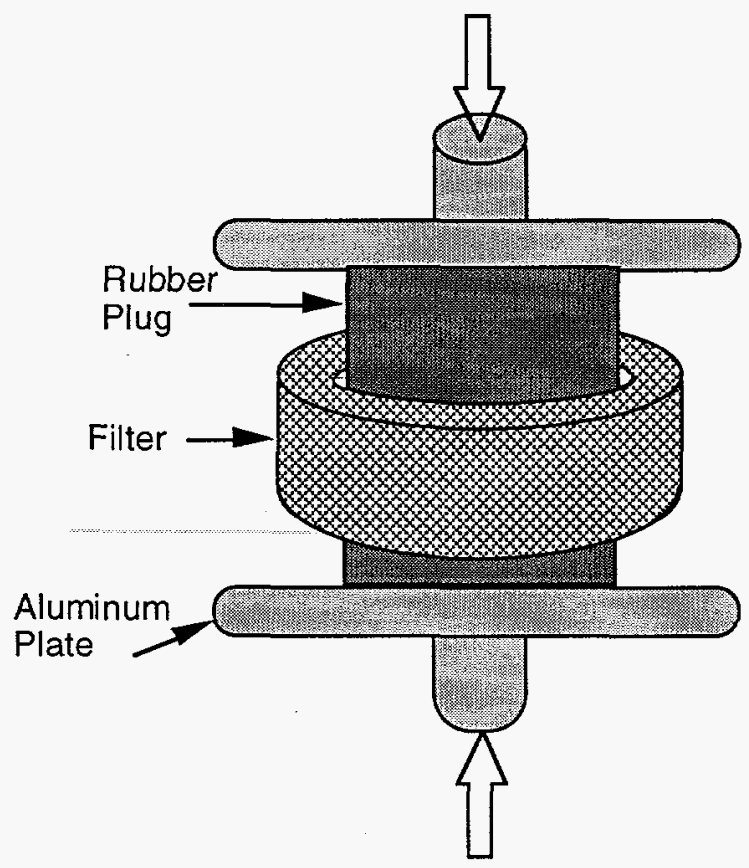

Fig. 4.

Schematic diagram of burst test setup.

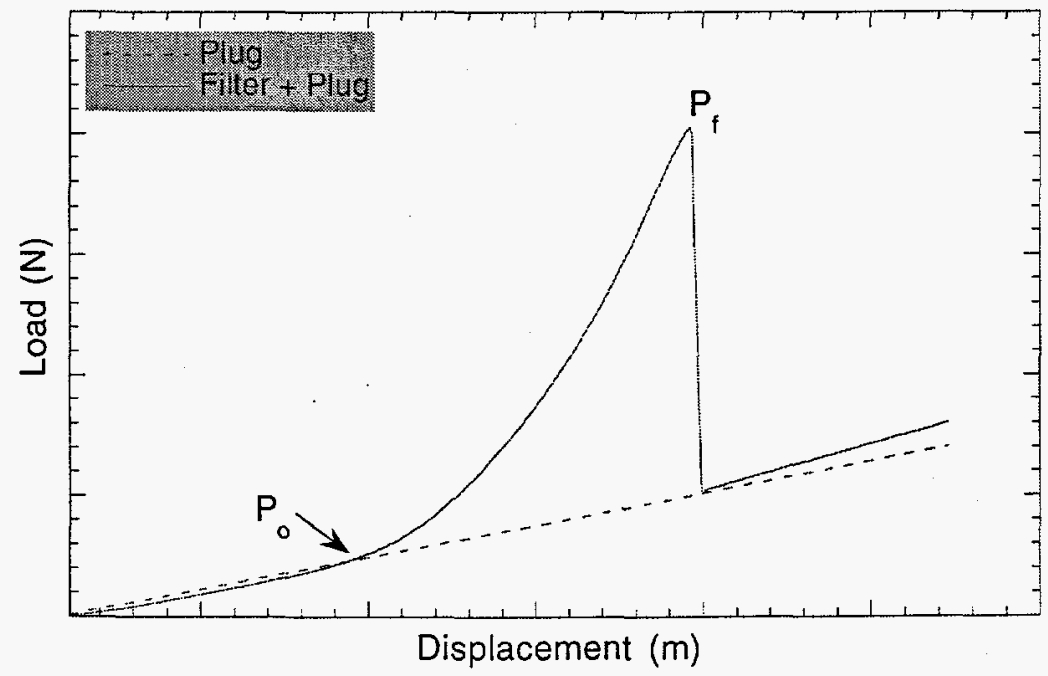

Fig. 5. Typical load-displacement plot for Nextel TM/SiC filter specimens. 
The maximum hoop stress $\left(\sigma_{t}\right)$ in a homogeneous cylinder occurs at the inner wall and is given by Eqs. 4 and 5 [6].

$$
\begin{aligned}
& \sigma_{t}=P^{L}\left(\frac{r_{o}^{2}+r_{i}^{2}}{r_{o}^{2}-r_{i}^{2}}\right), \\
& P^{L}=\frac{v}{(1-v)} \frac{\left(P_{f}-P_{o}\right)}{\pi r_{i}^{2}},
\end{aligned}
$$

where $\mathrm{p}^{\mathrm{L}}$ is the radial pressure on the inner wall of the filter; $r_{0}$ and $r_{i}$ are the outer and inner radii of the filter, respectively; $P_{f}$ is the maximum applied load at fracture; $P_{o}$ is the load at which the rubber plug makes contact with the filter; and $v$ is the Poisson's ratio (taken to $b e \approx 0.5$ ). The fracture load $P_{f}$ and contact load $P_{\circ}$ were obtained from the loaddisplacement plot. A limited number of specimens were evaluated by burst testing to compare the strength data with those obtained by O-ring compression testing. For the Nextel ${ }^{\mathrm{TM}} / \mathrm{SiC}$ composite filter specimens, the burst strength was measured at $6.4 \pm 0.22$ $\mathrm{MPa}$, lower than that obtained by O-ring tests. This difference is believed to be partly due to the larger specimen volume subjected to high stresses during burst testing than that in O-ring compression testing. A detailed analysis is given in Section 5 of this report.

\subsection{THERMAL SHOCK TESTING}

Thermal shock testing was performed on 1-in.-wide ring specimens machined from the filters. The ring specimens were insulated on their outer surfaces to simulate heat transfer conditions in service. These specimens were heated to preselected temperatures $\left(25-1100^{\circ} \mathrm{C}\right)$ in an electric furnace, as shown in Fig. 6. Subsequently, the specimens were quenched in silicone oil at a room temperature of $\approx 25^{\circ} \mathrm{C}$. Thermal shock damage was estimated by measuring strength of the ring specimens before and after thermal quench.

The results of the thermal shock experiments are shown in Fig. 7, which shows the retained strength (measured by O-ring compression test) of specimens subjected to varying degrees of thermal quench $(\Delta \mathrm{T})$. Vertical bars represent standard deviation where three or four specimens were tested. Other data points represent values for single specimen.

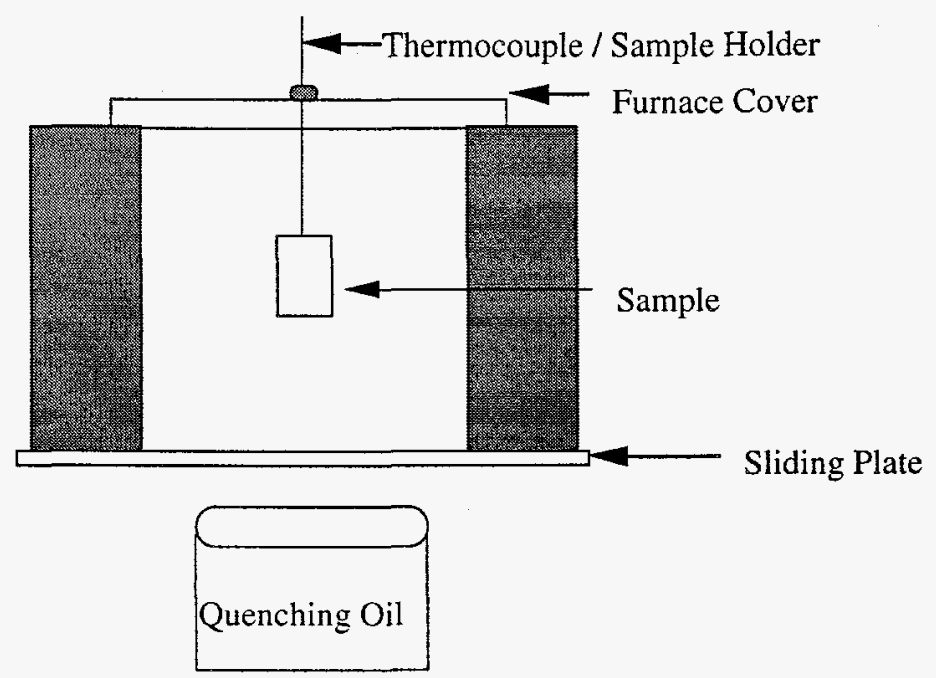

Fig. 6. Schematic diagram of thermal quench test apparatus. 

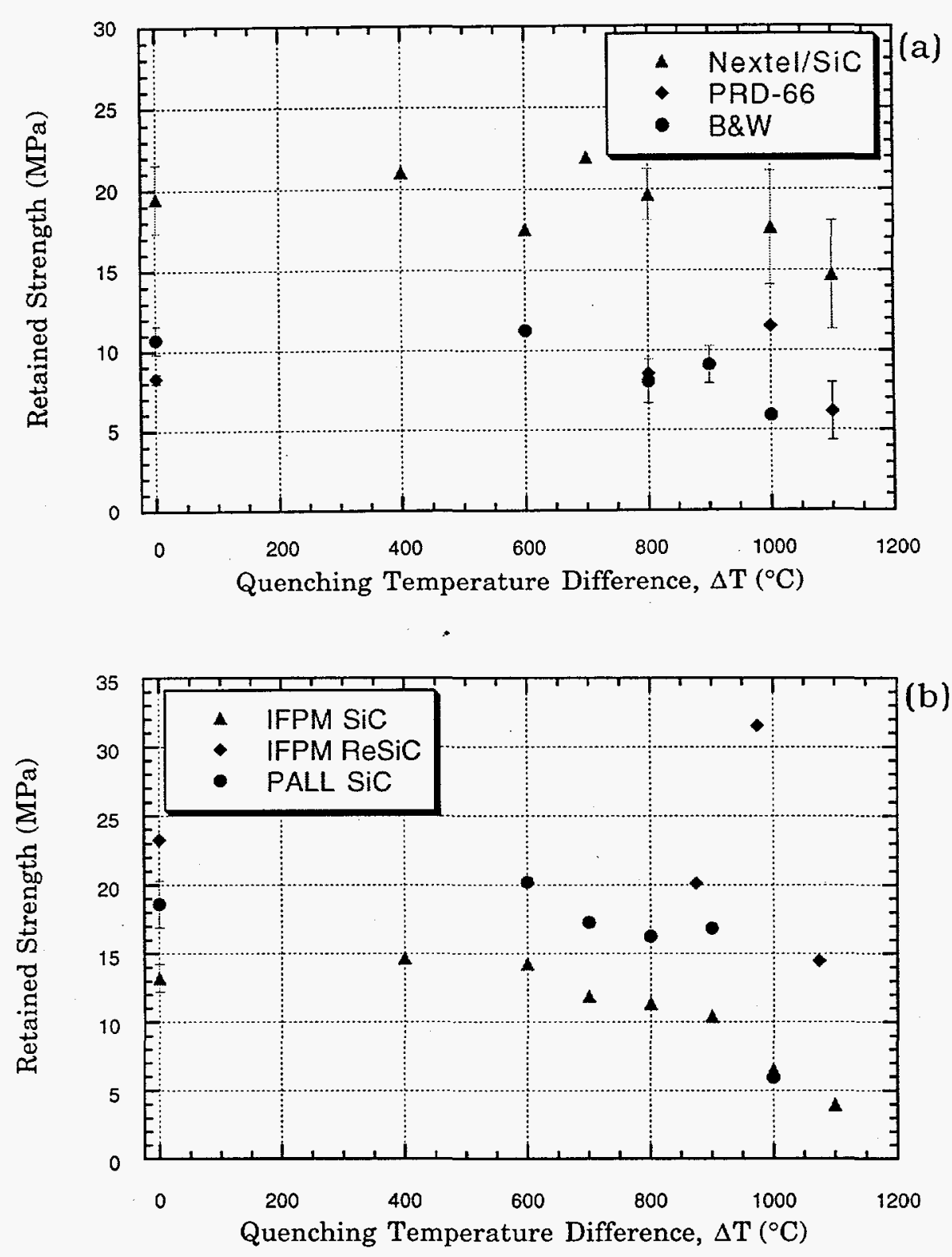

Fig. 7. Dependence of retained strength of ring specimens on quenching temperature difference $(\Delta T):(a)$ Nextel TM/SiC, PRD-66, and Babcock \& Wilcox composite filters; (b) IFPM monolith $\mathrm{SiC}$, IFPM monolith recrystallized $\mathrm{SiC}$, and PALL monolith SiC filters.

Results in Fig. 7(a) indicate that composite filters show little or no strength degradation when quenched from temperatures up to $\approx 900-1000^{\circ} \mathrm{C}$. At higher quenching temperatures, slow strength degradation was observed. Although, no significant strength degradation was observed, area under load-displacement plots decreased significantly (Fig. 8) in the specimens quenched from temperatures higher than $600^{\circ} \mathrm{C}$, indicating an increase in brittleness of composites quenched from these temperatures. This was clearly evidenced by the microstructural observations of the fracture surfaces, as shown in Fig. 9. The increase in brittleness is believed to be due to fiber/matrix interface degradation at these elevated temperatures. 


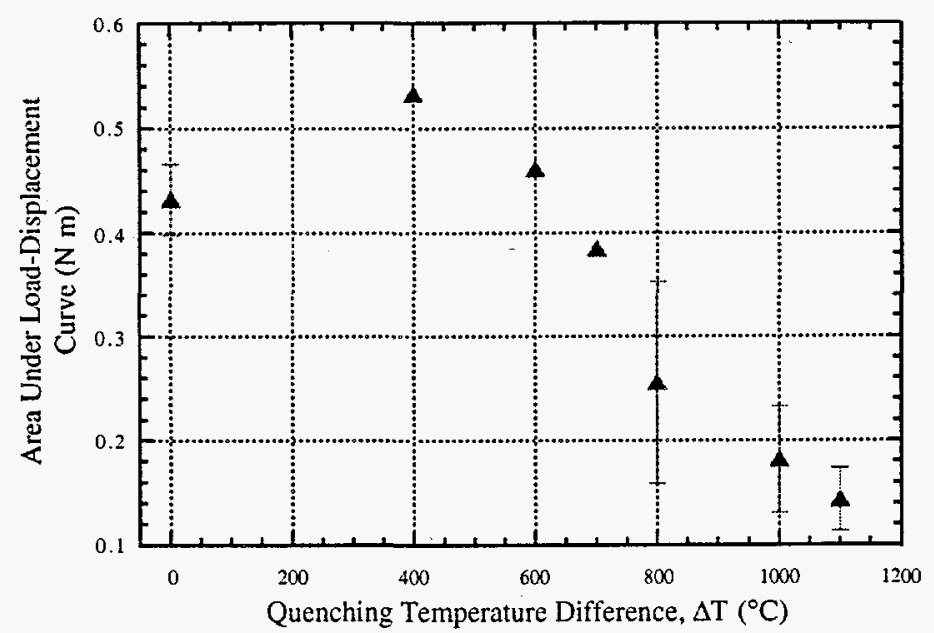

Fig. 8. Dependence of area under load-displacement curve for NextelTM/SiC ring specimens on quenching temperature difference $(\Delta T)$.

As shown in Fig. $7(\mathrm{~b})$, regular monolithic SiC filters showed no strength degradation when quenched from temperatures up to $\approx 700-900^{\circ} \mathrm{C}$. At higher temperatures, strength decreases at a relatively sharper rate. On the other hand, recrystallized monolithic SiC filter specimens showed higher initial strength and retained this strength to higher quenching temperatures than did the regular $\mathrm{SiC}$ filter specimens. This may be related to the difference in the strength of grain boundary phases in the two cases.

\section{EVALUATION OF THERMAL FATIGUE BEHAVIOR}

Thermal fatigue testing of both monolithic and composite filters was performed on 1-in.-wide ring specimens machined from the candle filters. These specimens were thermally cycled between room temperature and preselected elevated temperatures. The elevated temperatures $\left(800-1000^{\circ} \mathrm{C}\right)$ for thermal cycling were selected close to the critical quenching temperature observed in single-cycle thermal quench experiments. The ring specimens were insulated as before on their outer surfaces to simulate the heat transfer conditions in service. Thermal fatigue damage was estimated by measuring strength (by O-ring compression tests) of the ring specimens before and after thermal cycles.

The results of the thermal-fatigue experiments are shown in Fig. 10, which shows the retained strength of filter specimens as a function of thermal cycles. Vertical bars represent standard deviation, where three or four specimens were tested. Other data points represent values for a single specimen.

For thermal cycles between room temperature and $800-1000^{\circ} \mathrm{C}$, Nextel $\mathrm{TM} / \mathrm{SiC}, \mathrm{PRD}-$ 66 , and Babcock \& Wilcox composite filters show an $18-24 \%$ strength degradation up to three cycles. The strength decrease for the Nextel ${ }^{\mathrm{TM}} / \mathrm{SiC}$ composites is accompanied by $\approx 73-85 \%$ decrease in the area under the load-displacement plots, indicating an increase in the brittleness of the composites with increasing thermal cycles. As discussed previously, this is believed to be related to fiber/matrix interface degradation during thermal cycling. At higher numbers of thermal cycles, strength degradation remained unchanged. Similar behavior was observed for the monolithic filter specimens thermally cycled between room temperature and $800^{\circ} \mathrm{C}$. Initially, strength decreased by $15-28 \%$ up to about three cycles, beyond which the strength remained constant. On the other hand, for thermal cycling 

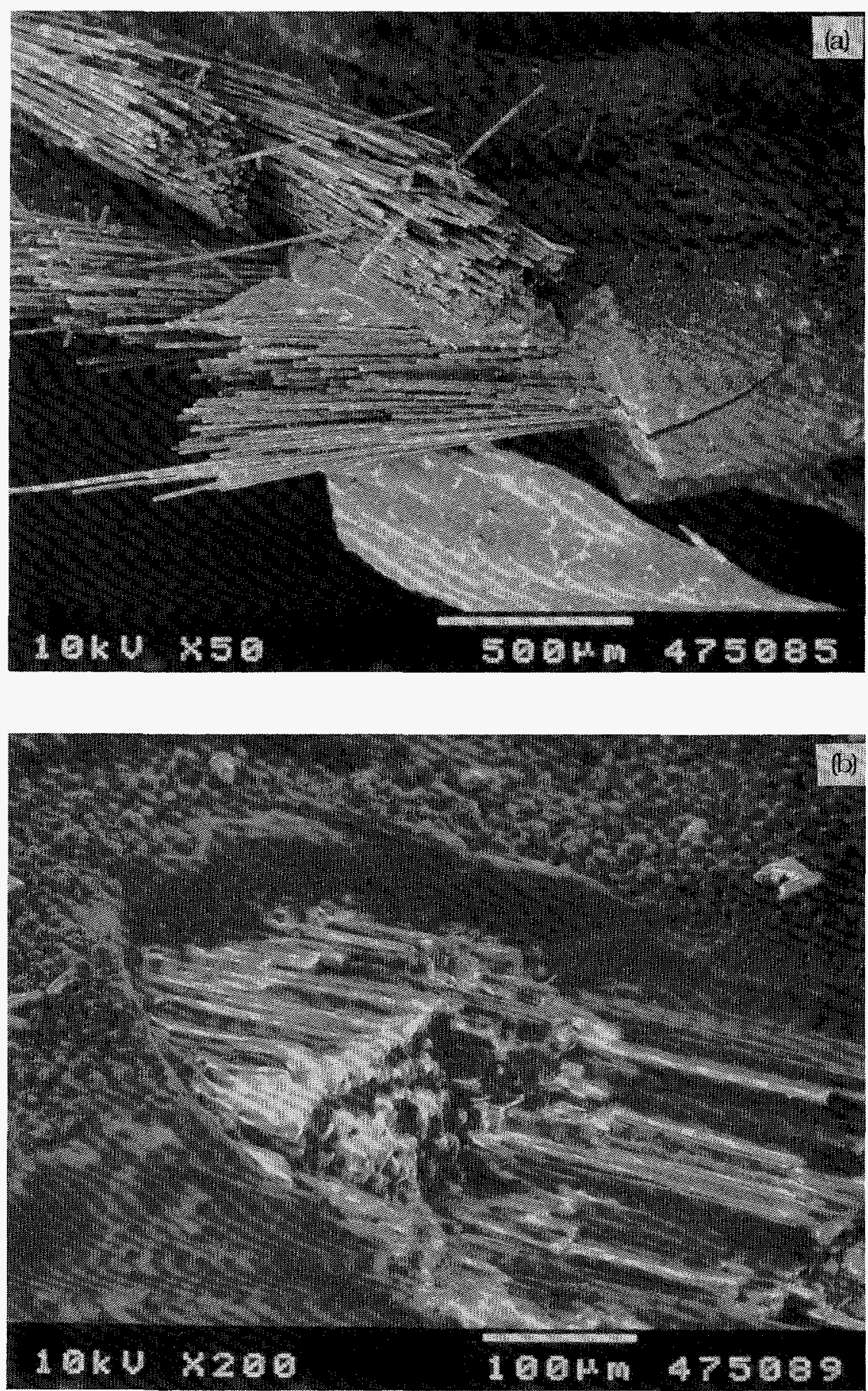

Fig. 9. Photomicrograph of fracture surface of Nextel $\mathrm{l}^{\mathrm{TM}} / \mathrm{SiC}$ ring specimens: (a) as-fabricated and (b) quenched from $1000^{\circ} \mathrm{C}$.

between room temperature and $900^{\circ} \mathrm{C}$, a large drop in strength was observed in filter specimens obtained from Pall Corp. The reason for this behavior is currently under investigation. Only one specimen was tested per condition because of the lack of availability of filter specimens. As expected, both monolithic and composite filters showed a slight decrease in strength values when thermally cycled from higher temperatures. 

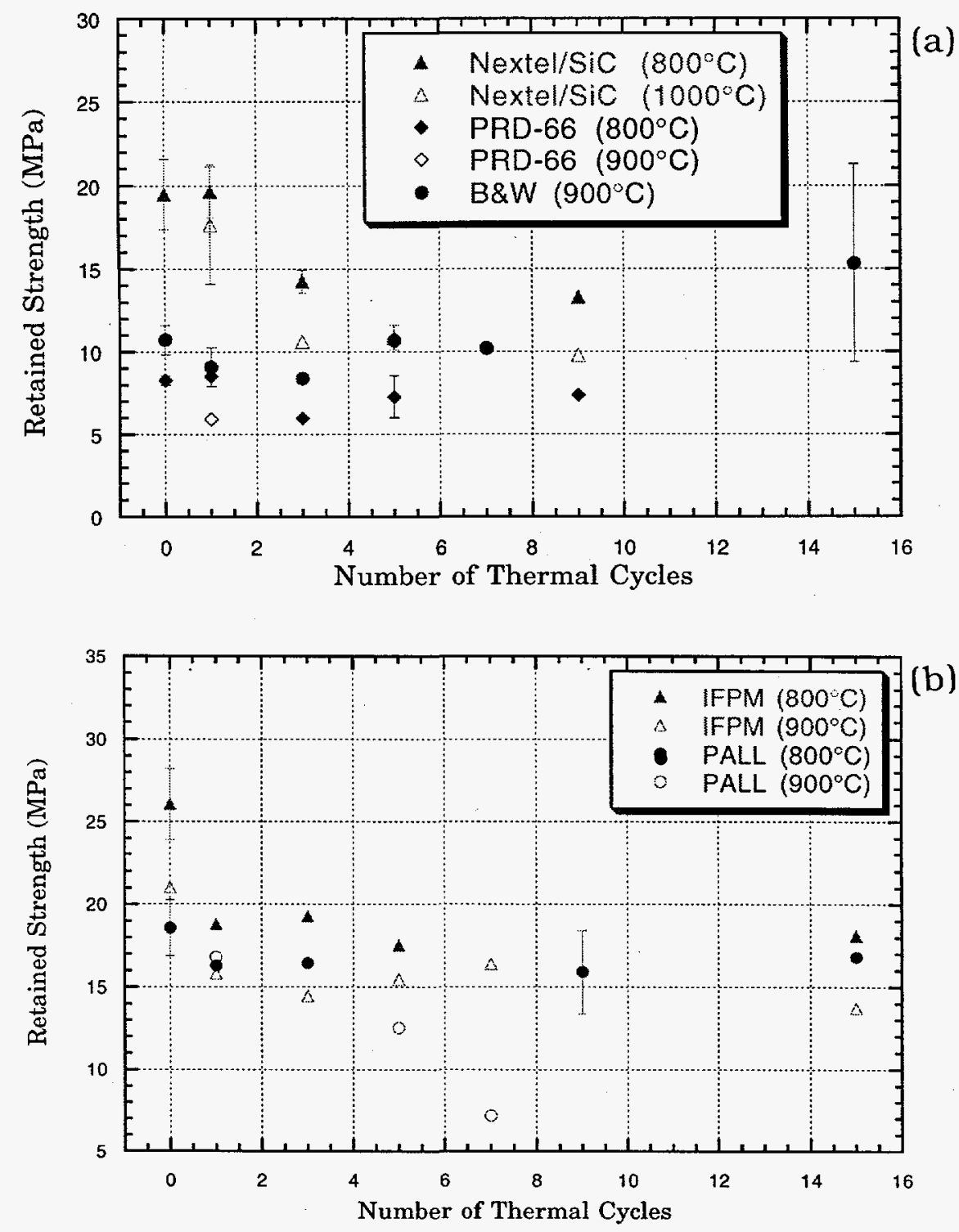

Fig. 10. Dependence of retained strength on number of thermal cycles: (a) NextelTM/SiC, PRD-66, and Babcock \& Wilcox composite filters; (b) IFPM monolithic SiC and Pall monolithic SiC filters.

\section{STRESS ANALYSIS}

Mechanical characterization of the $3 \mathrm{M}$ woven composite filter was achieved by three different types of tests:

- Axial tensile tests.

- O-ring burst tests with an internal plug.

- O-ring bending tests with and without prior thermal shock. 
While the first two types of tests generated primarily membrane stresses without significant bending, the third type of test generated primarily bending stresses in the filter. The filter had a woven Nextel ${ }^{\mathrm{TM}}$ fiber-reinforced $\mathrm{SiC}$ matrix composite cylinder that provided the bulk of the strength. Bonded to it on the outside was the filter element itself. Although not specifically intended, the filter element added significantly to the stiffness and strength of the filter. Micromechanical models were developed to account for the stiffness and strength of both the woven fiber-reinforced composite cylinder and the filter element. The elastic and fracture properties of the filter element were deduced from correlations with O-ring burst tests. The models were also used to interpret the tests conducted to determine the effects of thermal shock on the subsequent behavior of the filter in O-ring bending tests. The test results were closer to the predictions by the present models than those by a simple constant-strain model.

\subsection{GEOMETRY}

All test cylinders had a radius of $25 \mathrm{~mm}$ ( 1 in.). Those used for the axial tensile tests were $100 \mathrm{~mm}$ ( 4 in.) long and those used for the O-ring tests were $25 \mathrm{~mm}$ ( 1 in.) long. The geometry and loading of the composite test cylinder for the O-ring bending tests and O-ring burst tests using an internal plug are shown in Figs. $11 \mathrm{a}$ and $1 \mathrm{lb}$, respectively. The composite consisted of three families of woven Nextel ${ }^{\mathrm{TM}}$ fibers bonded to an SiC matrix by a CVD process. The first two families of fibers, which were at $\pm 30^{\circ}$ to the cylinder axis, consisted of three tows, each of which had 705-780 fibers of $10-12 \mathrm{~mm}$ diameter. The third family was a single axial tow consisting of 420 fibers of $8-10 \mathrm{~mm}$ diameter. For analytical purposes, each of the tows was modeled as fibers distributed uniformly in a matrix, (see Fig. 12). The weaving geometry (Fig. 13) also includes a typical representative volume element (RVE) that was used to determine analytically the stiffness properties of the composite. The composite was finally bonded on the outside to a filter element that was $\approx 1 \mathrm{~mm}$ thick, adding significantly to the elastic stiffness and strength of the composite.

\subsection{MECHANICAL PROPERTIES}

The mechanical properties of the various constituents used in the analyses are shown in Table 1. Properties of the Nextel ${ }^{\mathrm{TM}}$ fibers and $\mathrm{SiC}$ matrix were supplied by the manufacturer of the filter. Those of the filter element were not experimentally measured but were derived analytically from results of the O-ring burst tests with an internal plug, as will be discussed later.

\subsubsection{Axial Tensile Testing of Composite without Filter Element}

The in-plane stress resultants were related to the membrane strains by the stiffness coefficients $\mathrm{K}_{\mathrm{x}}^{\mathrm{C}}, \mathrm{K}_{\mathrm{y}}^{\mathrm{C}}$, and $\mathrm{K}_{\mathrm{xy}}^{\mathrm{C}}$ as follows:

$$
\begin{aligned}
& N_{x}=K_{x}^{C} \varepsilon_{x}+K_{x y}^{C} \varepsilon_{y}, \\
& N_{y}=K_{x y}^{C} \varepsilon_{x}+K_{y}^{C} \varepsilon_{y},
\end{aligned}
$$

where $N$ and $\varepsilon$ are the stress resultants and strains, respectively, and subscripts $x$ and $y$ denote axial and circumferential directions, respectively. For a plane stress axial tensile load of $B_{x}$, the axial strain was related to the axial load by 

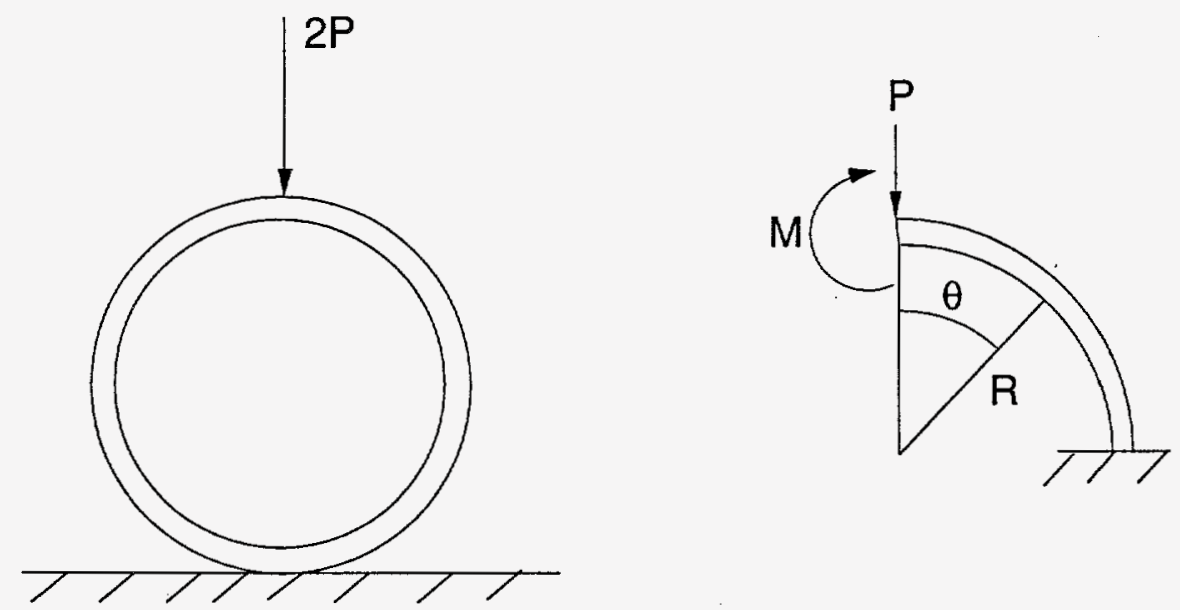

Fig. 11a. Typical setup for O-ring bending test. Because of symmetry, only one-quarter of the specimen was required for analysis.

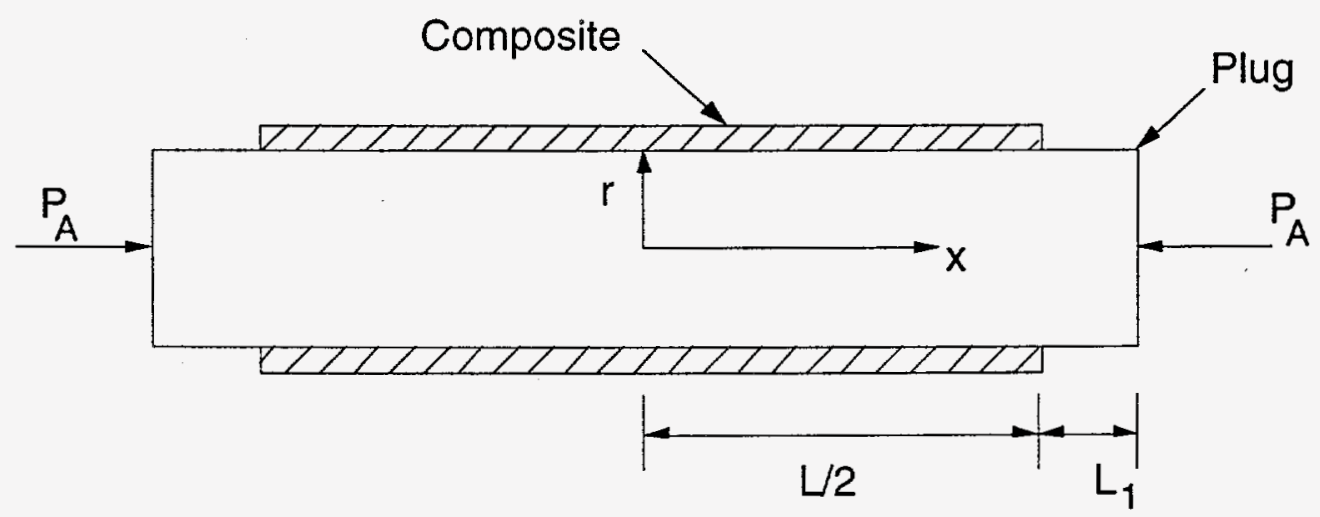

Fig. $11 \mathrm{~b}$. Typical burst test setup for $3 M$ filter with use of internal rubber plug.

$$
\varepsilon_{x}=\frac{\mathrm{Q}_{x}}{2 \pi \mathrm{R}\left(\mathrm{K}_{\mathrm{x}}^{\mathrm{c}}-\frac{\mathrm{K}_{\mathrm{xy}}^{\mathrm{C}}}{\mathrm{K}_{\mathrm{y}}^{\mathrm{C}}}\right)},
$$

where $\mathrm{R}$ is the radius of the cylinder. Appendix A provides the derivation of the stiffness coefficients in terms of the geometrical and mechanical properties of the components of the composite and the stresses in the components as functions of the applied loading. Note that the values of the stiffness coefficients changed during the tensile test because various components of the composite cracked sequentially and transferred their loads to the uncracked constituents.

According to the analysis (Fig. 14), matrix cracking of all tows (including axial tows,) occurred simultaneously at about one-half the peak load, resulting in a discontinuity in the predicted load-displacement curve. The tensile test conducted by $3 \mathrm{M}$ showed a nonlinear load-displacement curve due to progressive matrix cracking followed by typical brittle fracture behavior with a precipitous drop in load at final fracture. The experimental loaddisplacement curve did not show a large discontinuity before the final fracture load because the matrix strength is not a deterministic constant but has a distribution, and because the load shed by the cracked matrix was transferred to the surrounding fibers in a stable 

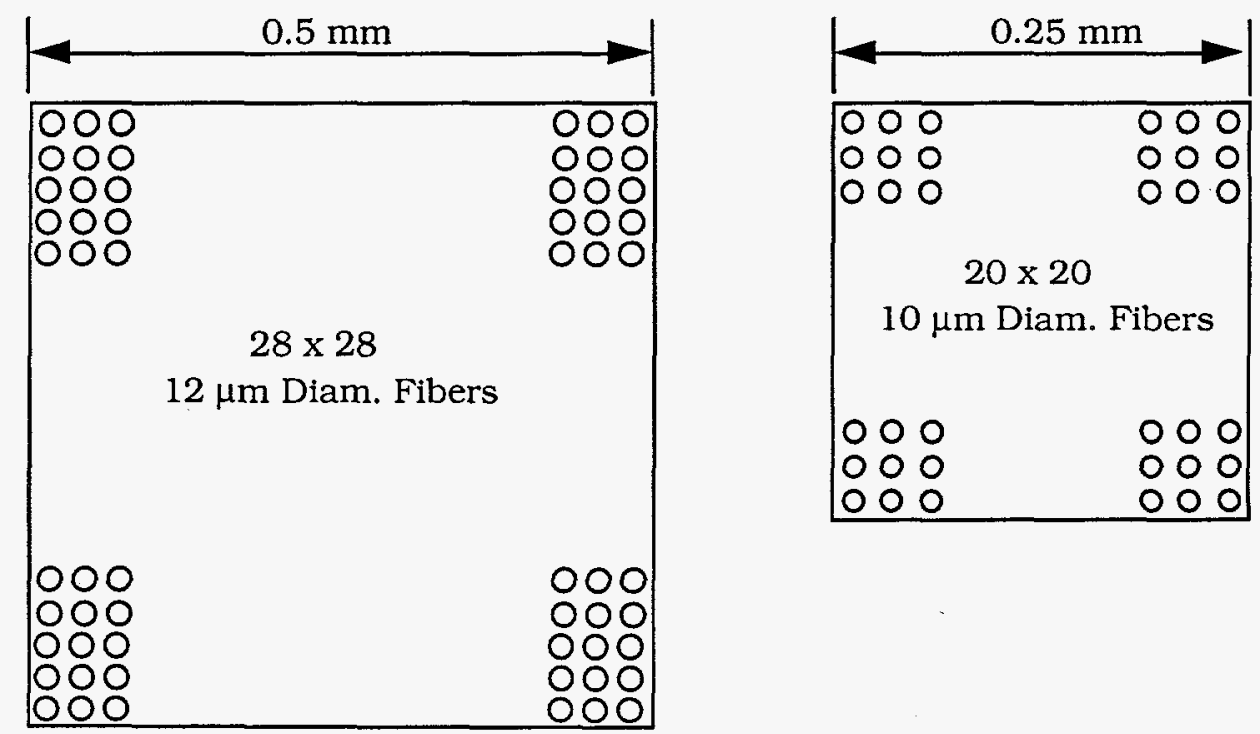

Single tow of Families 1 and 2

Fig. 12. Assumed distribution of fibers in a single tow. Each of families 1 and 2 consisted of three tows. All tows were assumed to be square in cross- section.
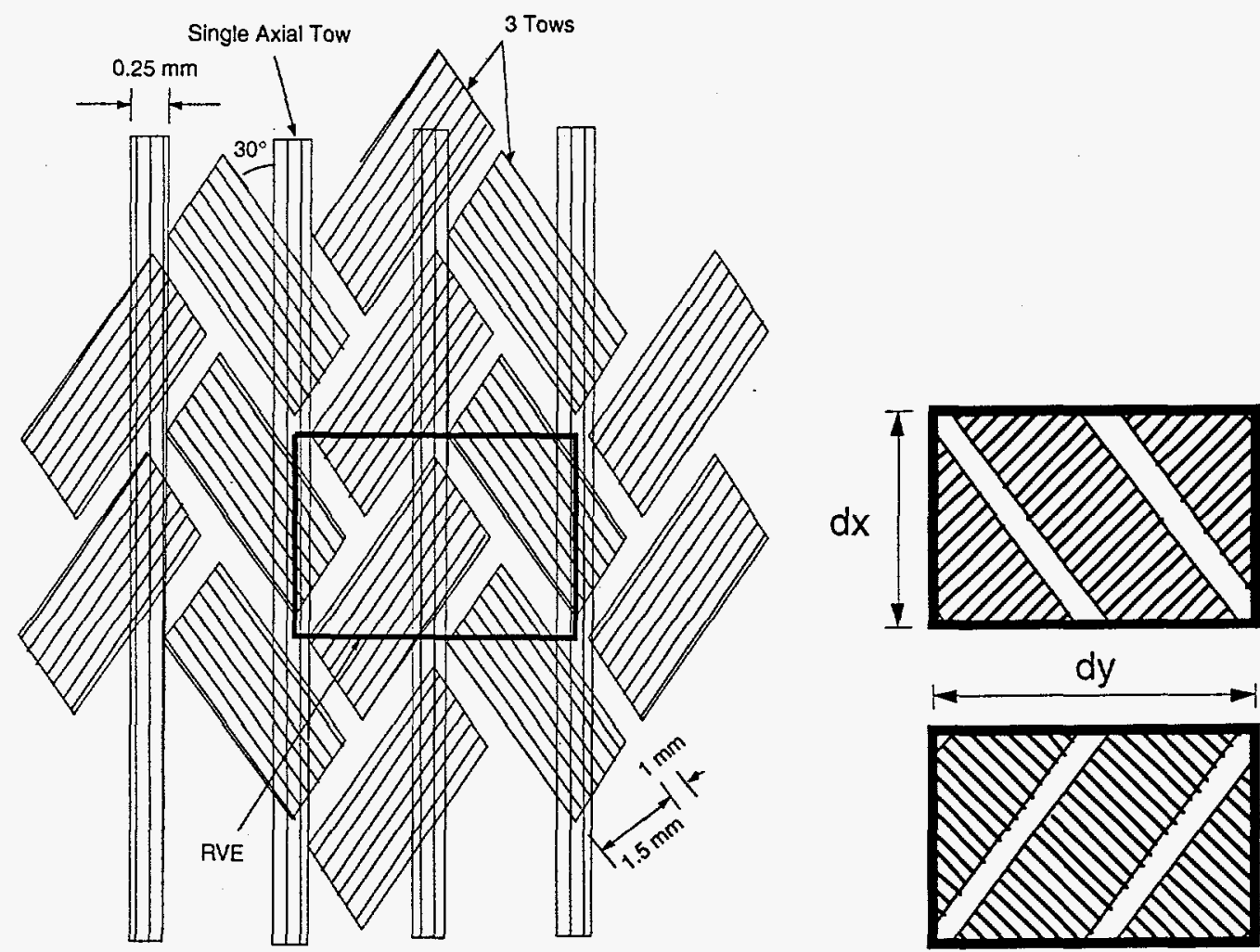

Fig. 13. Geometry and representative volume element (RVE) of $3 M$ woven composite. The two families of tows in a typical RVE are shown separately. Axial tows in RVE are not shown. 
Table 1. Mechanical properties of constituents of $3 M$ filter used in model calculations

\begin{tabular}{lccc}
\hline \multicolumn{1}{c}{ Parameter } & Nextel $^{\text {TM }}$ Fiber & SiC Matrix & Filter Element \\
\hline Young's Modulus (GPa) & 138 & 410 & $17.8^{\mathrm{a}}$ \\
Poisson's ratio & 0.3 & 0.19 & 0.3 \\
Fracture Strength (MPa) & 1700 & $140-170$ & $17-24^{\mathrm{a}}$ \\
Thermal Expansion Coeff. & 3 & 4 & - \\
$\left(10^{-6} /{ }^{\circ} \mathrm{C}\right)$ & & & \\
\hline
\end{tabular}

aEstimated from O-ring burst tests.

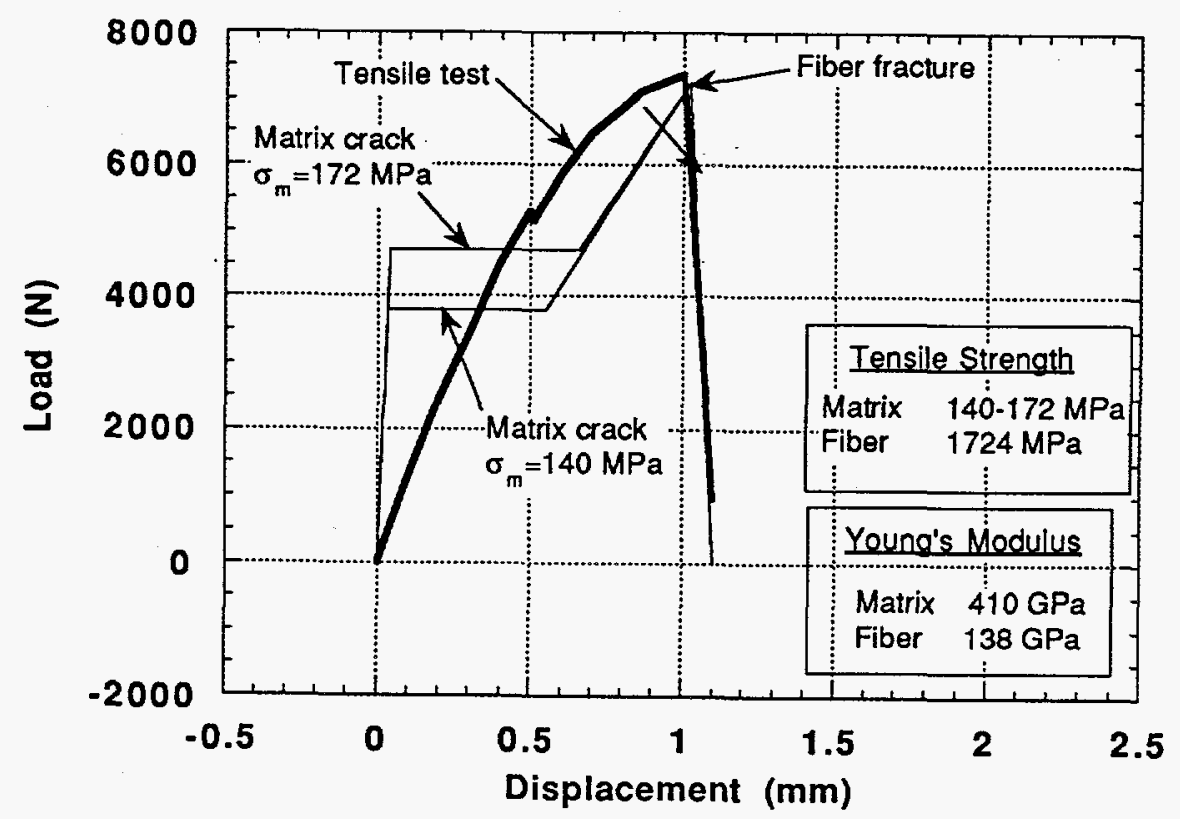

Fig. 14. Predicted vs. observed load-displacement diagram for axial tensile test on composite cylinder (without filter). Predicted curves are based on fiber fracture strength of $1724 \mathrm{MPa}$.

manner. The predicted peak load corresponded to fiber fracture of all tows simultaneously and agreed fairly well with the experimentally observed value. In reality, the weakest fibers in one of the tows would initiate fracture, and the load carried by it would be transferred to neighboring fibers of the same family and cause further fracture and load redistribution and so on, in an escalating fashion.

\subsubsection{Burst Testing with an Internal Plug}

As before, the in-plane stress resultants in the composite were related to the membrane strains by the stiffness coefficients $\mathrm{K}_{\mathrm{x}}, \mathrm{K}_{\mathrm{y}}$, and $\mathrm{K}_{\mathrm{xy}}$ as follows:

$$
\begin{aligned}
& N_{x}=K_{X} \varepsilon_{x}+K_{x y} \varepsilon_{y} . \\
& N_{y}=K_{x y} \varepsilon_{x}+K_{y} \varepsilon_{y} .
\end{aligned}
$$


A detailed analysis (given in Appendix B) showed that the axial loads transmitted by friction from the plug to the composite were negligible compared to the hoop loads. Therefore, we assumed that the friction effects at the interface between the rubber plug and the composite O-ring were negligible, so that after contact the composite experienced hoop stress only, i.e., $N_{X}=0$. In such a case, the above stress-strain relationship reduced to the following :

$$
N_{y}=E_{y} \varepsilon_{y}=\left(K_{y}-\frac{K_{x y}^{2}}{K_{x}}\right) \varepsilon_{y} .
$$

The initial radial clearance $u_{0}$ between the plug and the O-ring was closed at an axial pressure of $\mathrm{p}_{\mathrm{Ao}}$, where

$$
\mathrm{p}_{\mathrm{Ao}}=\mathrm{E}_{\mathrm{R}} \varepsilon_{\mathrm{Ao}}=\frac{\mathrm{E}_{\mathrm{R}} \varepsilon_{\mathrm{o}}}{v_{\mathrm{R}}},
$$

where $\varepsilon_{0}=u_{0} / R, R$ is the radius of the plug, and $E_{R}$ and $v_{R}$ are the Young's modulus and Poisson's ratio of the plug, respectively. Beyond initial contact at an axial pressure $p_{A}$, an interfacial pressure $\mathrm{p}$ and the following strains were developed:

- $\quad$ Plug

$$
\begin{aligned}
& \varepsilon_{r}=\varepsilon_{y}=\frac{v_{R} p_{A}}{E_{R}}-\frac{\left(1-v_{R}\right) p}{E_{R}} . \\
& \varepsilon_{A}=\frac{p_{A}}{E_{R}}-\frac{2 v_{R} p}{E_{R}} .
\end{aligned}
$$

- O-Ring

$$
\varepsilon_{\mathrm{y}}=\frac{\mathrm{pR}}{\mathrm{E}_{\mathrm{y}}} .
$$

Compatibility at the interface required

$$
\varepsilon_{y}(\mathrm{Plug})-\varepsilon_{\mathrm{y}}(\mathrm{O} \text {-ring })=\varepsilon_{\mathrm{o}}
$$

Eqs. 8, 9(a-c), and 10 were solved to give

$$
p=\frac{\frac{v_{R}}{1-v_{R}}\left(p_{A}-p_{A o}\right)}{1+\frac{E_{R} R}{\left(1-v_{R}\right) E_{r}}}=\frac{1}{2 v_{R}}\left(1-\frac{E_{R}}{E_{1}}\right)\left(p_{A}-p_{A o}\right),
$$

where

$$
E_{1}=\frac{p_{A}-p_{A o}}{\varepsilon_{A}-\varepsilon_{A o}}=E_{R} \frac{\frac{E_{R} R}{E_{y}}+1-v_{R}}{\frac{E_{R} R}{E_{y}}+\left(1+v_{R}\right)\left(1-2 v_{R}\right)} .
$$


Thus, the predicted axial stress-strain curve of the rubber plug was bilinear, with $\mathrm{E}_{\mathrm{R}}$ and $E_{1}$ denoting the slopes before and after contact with the O-ring, respectively. However, until now the lengths of the plug and the composite were assumed to be equal. In the tests, the plug was longer than the filter, and therefore the measured displacement of the plug included an additional component of displacement from a portion of the plug that lay outside the filter. Because this portion of the plug was usually much shorter than the diameter of the plug, a simple uniaxial formula grossly overestimated the displacements. The component of displacement from the portion of the plug lying outside the composite was determined experimentally by replacing the filter with a tube of exactly the same length and internal radius but of a much greater stiffness (a 51-mm [2 in.]-diameter steel tube with wall thickness of $12 \mathrm{~mm}$ [0.5 in.] was used). With such a tube, the total axial displacement of the plug per unit axial load was given by

$$
u(\text { total })=\frac{1}{\pi R^{2} E_{R}}\left[\left(1-2 v_{R}\right)\left(1+v_{R}\right) L+2 \chi L_{1}\right]
$$

where $\mathrm{L}$ is the length of the composite, $2 \mathrm{~L}_{1}$ is the total length of the plug lying outside the filter, and $\chi(<1)$ is an effective length factor. The final slope at $3 \mathrm{~mm}$ axial displacement was found to be $2.5 \times 10^{-4} \mathrm{~mm} / \mathrm{N}$. Substituting this value in the above formula, we determined the following values of $\chi$ as a function of the Poisson's ratio of rubber:

\begin{tabular}{lc}
\hline Poisson's ratio & $\chi$ \\
0.495 & 0.081 \\
0.5 & 0.111 \\
\hline
\end{tabular}

An average value of $\chi=0.1$ was used in the calculations. The measured load displacement curve (Fig. 15) for the composite with the filter element was first replaced by a bilinear curve with the slope of the steeper segment equal to $5.9 \times 10^{-4} \mathrm{~mm} / \mathrm{N}$. The slope of the steeper segment was matched by the calculated slope by choosing the following value for the filter element stiffness $\mathrm{K}_{\mathrm{F}}: \mathrm{K}_{\mathrm{F}}=25,500 \mathrm{MPa}-\mathrm{mm}$.

For a thickness of $1 \mathrm{~mm}$, this corresponded to a Young's modulus of $25.5 \mathrm{GPa}$ (3.7 $\mathrm{x}$ $10^{6} \mathrm{psi}$ ) for the filter element. The model then predicted that at an axial load of $2000 \mathrm{~N}$, the maximum stresses in the matrix and fibers of the inclined tows were 140 and $43 \mathrm{MPa}$, respectively. Maximum stress in the filter element was $17 \mathrm{MPa}$. Figure 15 shows the experimental versus calculated load displacement plot for the composite, including the filter element. The origin of the steeper section of the calculated bilinear curve was taken at $0.002 \mathrm{~m}$ and $296 \mathrm{~N}$.

If the matrix fracture stress was $140 \mathrm{MPa}$ and the filter fracture stress $>17 \mathrm{MPa}$, the matrix would crack and its load would be transferred to the fibers and the filter element, which would have their stresses increased to 64 and $24 \mathrm{MPa}$, respectively. If the fracture stress of the filter was $\leq 24 \mathrm{MPa}$, it would crack and transfer its load to the fibers, which would have their stress increased to $3100 \mathrm{MPa}$, causing failure of the filter by fiber fracture because the reported fiber fracture stress of $1700 \mathrm{MPa}$ was greatly exceeded.

If, on the other hand, the matrix strength was $>140 \mathrm{MPa}$ and the fracture strength of the filter element was $17 \mathrm{MPa}$, then at an axial load of $2000 \mathrm{~N}$. the filter element would crack first and the matrix and fiber stresses would be increased to $400 \mathrm{MPa}$ and $125 \mathrm{MPa}$. 


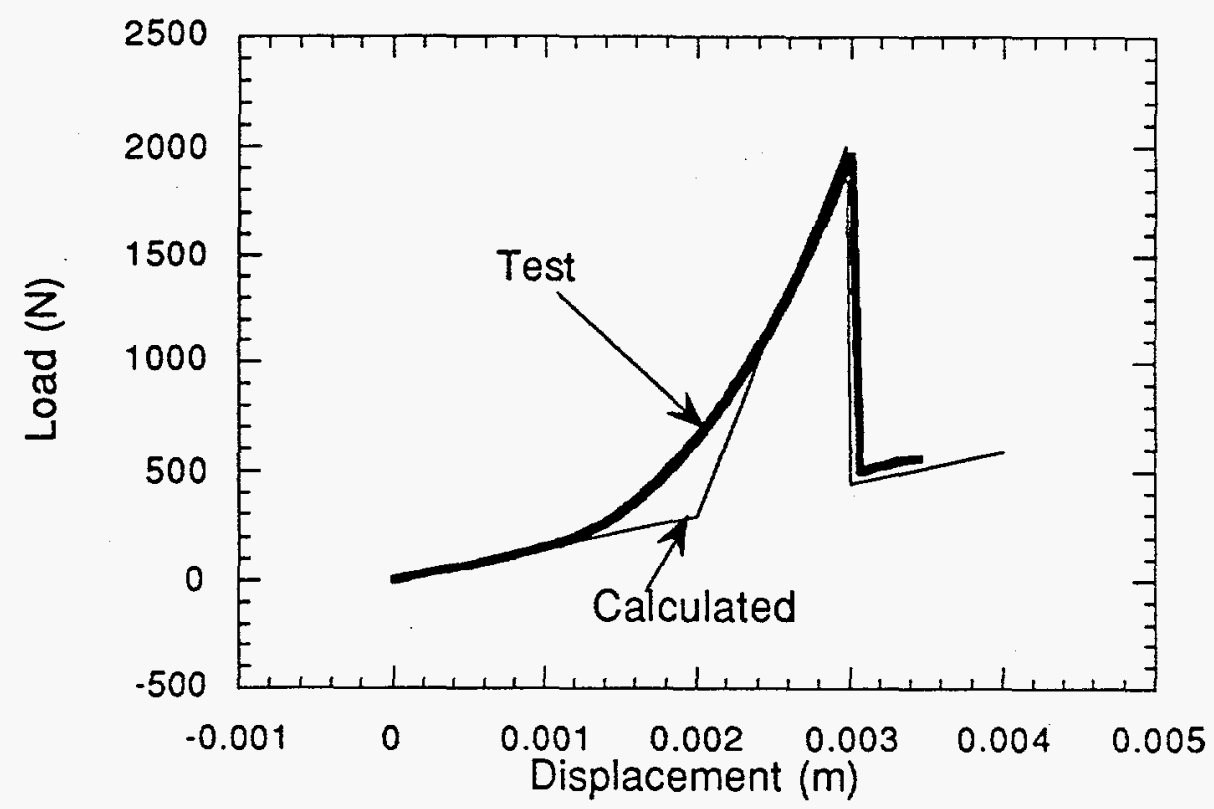

Fig. 15. Calculated vs. experimentally measured load-displacement curves of plug for composite (with filter element).

respectively. As a result of the high stress, the matrix would crack, which in turn would be followed by fiber fracture and failure of the whole filter, as before. Thus, as long as the fracture strength of the filter element was 17 to $24 \mathrm{MPa}$, the filter is predicted to fail at an axial load of $2000 \mathrm{~N}$.

Figure 16 shows a similar plot for the composite without the filter element. The origin of the steeper section of the calculated bilinear curve was taken at $0.001 \mathrm{~m}$ and $148 \mathrm{~N}$. In this case, the calculated curve had a discontinuity at a load of $700 \mathrm{~N}$, where the matrix was predicted to fracture. After the matrix fracture, the composite load displacement curve was predicted to follow a shallower slope until the maximum fiber stress reached the fracture stress, $1700 \mathrm{MPa}$, at an axial load of $1100 \mathrm{~N}$.

The comparison between the calculated and experimental load displacement curves was reasonable for the composite without the filter element. The experimental curve did not show a discontinuity except at peak load. The calculated curve showed an additional discontinuity at a lower load because the matrix fracture strength was assumed to be a deterministic constant. In reality, because the matrix did not crack simultaneously everywhere, but cracked gradually because of a distribution in strength, the discontinuity was smoothed out.

To summarize, for the composite with the filter element, the slope and the peak load could be predicted quite well if we assumed that the filter material had the following properties:

$$
\mathrm{E}_{\mathrm{F}}=25.5 \mathrm{GPa} \text { and fracture strength } \sigma_{\mathrm{F}}=17-24 \mathrm{MPa} .
$$

In this case, a gradual or sudden cracking of the matrix did not lead to a discontinuity in the calculated load displacement plot, because the presence of the relatively stiff filter element ensured that there was very little difference between the stiffness of a composite with an uncracked matrix and that of a composite with a fully cracked matrix. 


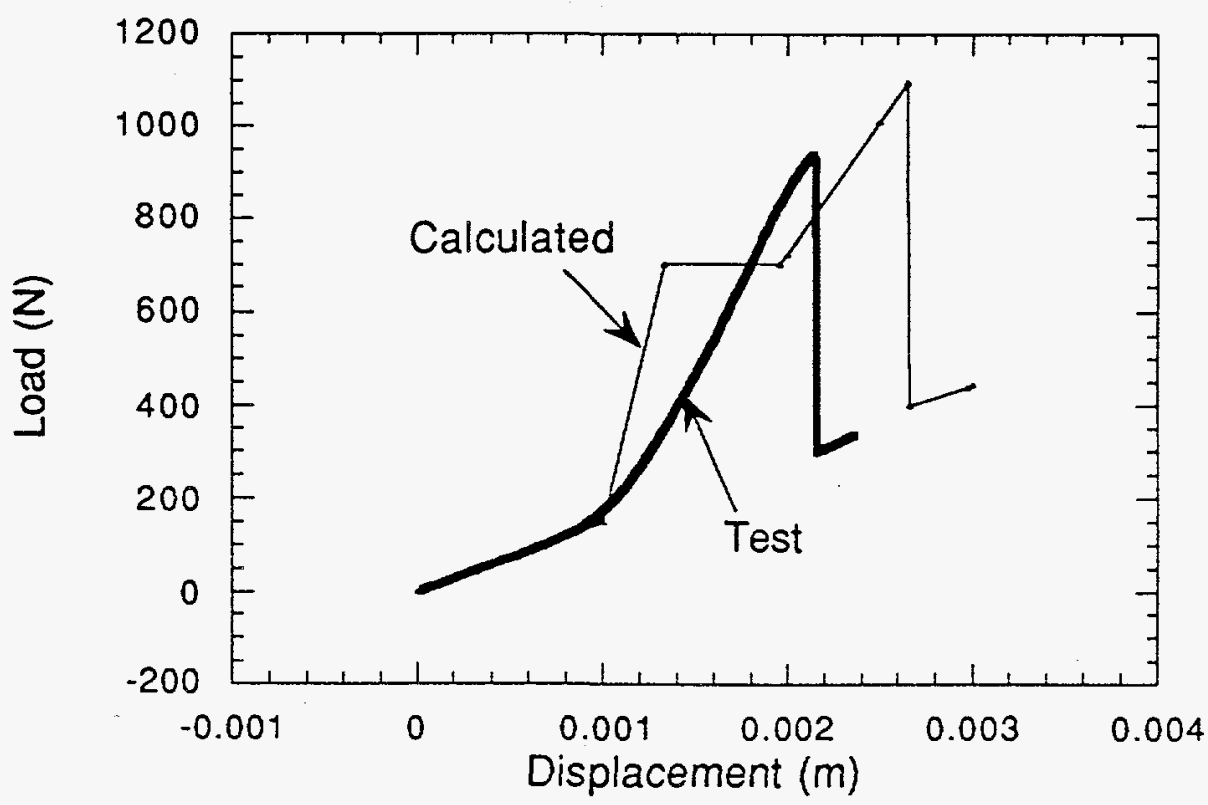

Fig. 16. Calculated vs. experimentally measured load-displacement curves of plug for composite (without filter element).

The observed difference in the final fracture surface appearance of the two composites could be qualitatively justified on the basis of the final fiber stresses. Note that the final fiber fracture of the composite with the filter element occurred suddenly after the fracture of the filter element, when all of the hoop load from the filter element was transferred to the fibers. The high calculated fiber stress $(3100 \mathrm{MPa})$ indicated that the driving force for fiber fracture was high. Consequently, the final fracture occurred by cracking of both families of fibers and the final fracture appeared to propagate in the axial direction.

On the other hand, in the composite without the filter element, the fiber stresses increased gradually before failure. As a result, the weaker fibers in one fiber family failed first, promoting more failure of nearby fibers of the same family, which had to make up the difference. This triggered the failure of more fibers of the same family, resulting in a fracture surface that appeared to be a shear fracture, i.e., at $45^{\circ}$ to the axial direction.

\subsubsection{O-Ring Bending Tests}

Figure 1la shows a typical set up for an O-ring bending test, also referred to as O-ring compression test. Displacement under the load point was determined by an application of Castigliano's theorem as described below. Ignoring the contributions of the extensional and shear strain energies, the strain energy of the system per unit axial length is given by

$$
\mathrm{U}=\frac{1}{2} \int_{0}^{\pi / 2} \frac{\mathrm{M}_{\mathrm{y}}^{2}}{\mathrm{D}_{\mathrm{y}}} \mathrm{Rd} \theta,
$$

where $M_{y}(=M-P R \sin \theta)$, and $D_{y}^{\prime}$ are the circumferential bending moment and bending stiffnesses per unit axial length, respectively. Note that before initial cracking, $D_{y}$ ' was a constant and could be taken outside the integral sign. However, as cracking spread from under the load point $\left(\theta=0^{\circ}\right)$ and eventually from $\theta=90^{\circ}, D_{y}^{\prime}$ became a function of $\theta$ as well as of the thickness of the cracked matrix. The moment $M$ and displacement $d$ under the load point were then obtained by solving the following two equations: 


$$
\frac{\partial \mathrm{U}}{\partial \mathrm{M}}=0 \text { and } \delta=\frac{\partial \mathrm{U}}{\partial \mathrm{P}}
$$

Noting that the axial length of the cylinder was $W$ so that the total measured load was $\mathrm{Q}=2 \mathrm{PW}$ and that the load point displacement in the O-ring test was $\mathrm{D}=2 \mathrm{~d}$, we obtained

$$
M=\frac{\mathrm{QR}}{2 \mathrm{~W}} \frac{\int_{0}^{\pi / 2} \frac{\operatorname{Sin} \theta}{\mathrm{D}_{\mathrm{y}}} \mathrm{d} \theta}{\int_{0}^{\pi / 2} \frac{1}{\mathrm{D}_{\mathrm{y}}} \mathrm{d} \theta}
$$

and

$\Delta=\frac{\mathrm{QR}^{3}}{\mathrm{~W}} \int_{0}^{\pi / 2} \frac{\operatorname{Sin}^{2} \theta}{\mathrm{D}_{\mathrm{y}}^{\prime}} \mathrm{d} \theta-2 \mathrm{MR}^{2} \int_{0}^{\pi / 2} \frac{\operatorname{Sin} \theta}{\mathrm{D}_{\mathrm{y}}} \mathrm{d} \theta$.

Before cracking onset, Eqs. 16a-b reduce to

$M=\frac{Q R}{\pi W}$

and

$$
\Delta=\frac{\mathrm{QR}^{3}}{\mathrm{WD}_{\mathrm{y}}}\left(\frac{\pi}{4}-\frac{2}{\pi}\right) .
$$

\subsubsection{O-Ring Bending Test of Composite without Filter Element}

Analytical prediction of the complete load-displacement curve for the O-ring test was complicated by several factors. First, the onset of matrix cracking by bending did not lead to a total loss of bending-moment carrying capability of the matrix. Second, in contrast to the tensile test, the stresses and bending moment varied around the circumference of the cylinder. Thus cracking was initiated at the ID surface under the load point $\left(\theta=0^{\circ}\right)$. With increasing load, cracking progressed not only through the thickness of the matrix but also around the circumference. Finally, with increasing load, a second crack front was initiated at the OD surface at $\theta=90^{\circ}$, which also propagated in both thickness and circumferential directions. By the time final fracture occurred, the cylinder was flattened significantly, causing geometrical nonlinearities that the current linear analysis could not account for. All these complexities led to an experimentally observed, staircase-type load-displacement curve that was very difficult to derive from a rigorous micromechanical model.

To enable an analysis, several simplifying assumptions were made, as discussed in Appendix A. Using the current model, we calculated variations of the fraction of matrix that cracked, composite bending stiffness, and maximum fiber stress with the applied bending moment at any section of the composite, as shown in Fig. 17. Because the torsional and bending stiffnesses of the tows depended strongly on the longitudinal shear bond between the three tows in each family and the interlaminar bond between the three families of interweaving tows, two extreme conditions were used for the calculations. First, the longitudinal shear and the interlaminar bonds between the tows in both families $\left( \pm 30^{\circ}\right)$ were assumed to be undamaged (Fig. 17a), and second, they were assumed to be 


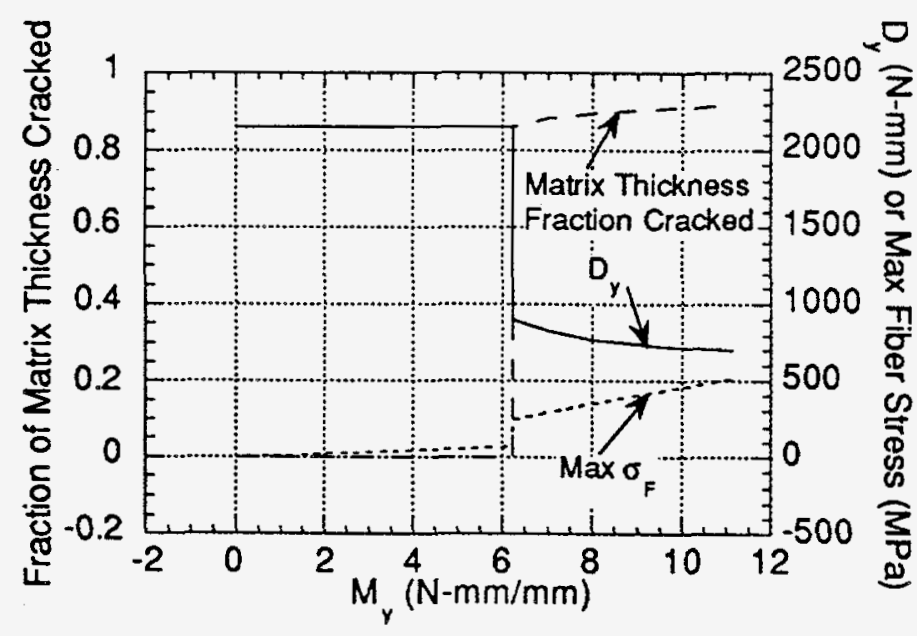

(a)

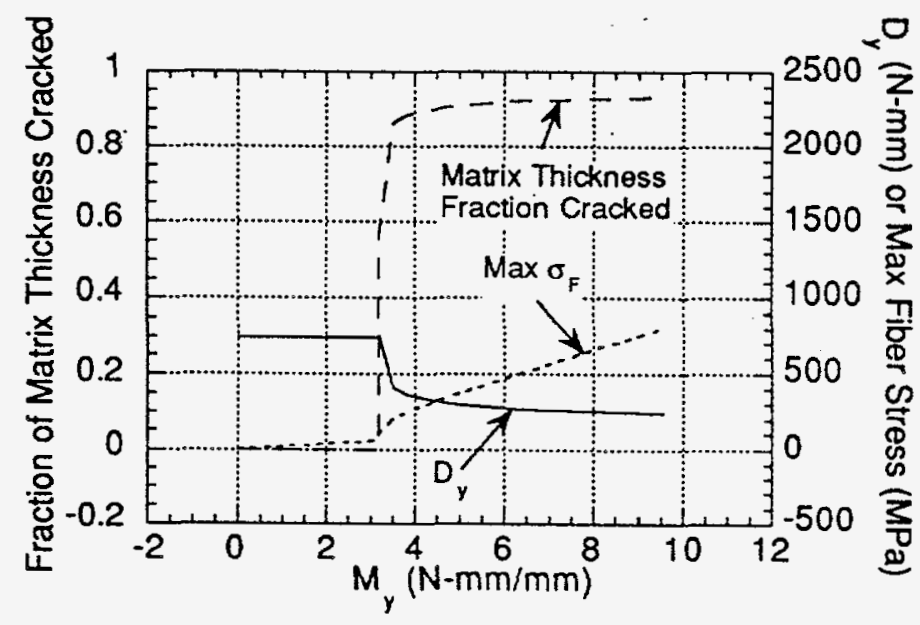

(b)

Fig. 17. Variations of fraction of matrix thickness that cracked, composite bending stiffness, and maximum fiber stress with applied bending moment when longitudinal shear and interlaminar bonds between tows are (a) undamaged and (b) broken. At the threshold bending moment, cracks were predicted to initiate and penetrate a large fraction of thickness.

completely broken (Fig. 17b). In both cases, below certain threshold bending moments, the section was uncracked and the bending stiffness was a constant. At the threshold bending moment, matrix cracking was initiated; equilibrium and the fracture criterion for the matrix required the matrix to crack through a large fraction of the section in a discontinuous but stable manner, leading to a significant reduction of the composite bending stiffness. Simultaneously with matrix cracking, stresses in the fibers increased discontinuously, because the load carried previously by the matrix was transferred to the fibers after cracking.

For the the present calculations, composite stiffness was idealized to vary in a steplike fashion, having a relatively low constant value after cracking, but ignoring the small changes that occurred during increased cracking. This idealization allowed us to bypass the need to compute the detailed progress of cracking through the thickness of the matrix 
at every section. The propagation of the cracked zone around the circumference of the cylinder was computed iteratively with Eqs. 16a-b and the threshold moment used as a fracture criterion for the matrix.

A comparison of O-ring test data and computed load-displacement curves, using two extreme conditions of the longitudinal shear bond between the tows, is shown in Fig. 18. The initial rising part of the test curve was close to the predicted curve, based on the assumption of an undamaged bond. Matrix cracking under the load point $\theta=0^{\circ}$ was predicted to initiate well before the peak load was reached. However, the test curve reached a peak at a point close to the predicted onset of a second crack front at $\theta=90^{\circ}$. The reason for the drop in experimental load could not be established unequivocally. According to the model, fiber fracture should not have occurred at the peak load. A possible scenario consisted of the loss of bond between the tows of same family, as well as of that between different families (next lower curve), followed by loss of all shear capability due to shear cracking (next lower curve), and finally complete cracking of the matrix (lowest curve). If this scenario were correct, then by choosing the interfacial bond strengths appropriately, the computed load-displacement curve could be made to cascade down from the highest curve to the lowest curve of Fig. 18 in much the same way as during the test. Figure 18 also shows a curve based on the constant strain assumption, which led to an upper bound to the test data, as expected.

To consider the potential for fiber fracture, variation of the maximum fiber stress with bending moment are plotted in Fig. 19 for various assumptions in the model. For typical bending moments (5-10 N-mm/mm), fiber fracture occurred only if the matrix could not bear any load and the fibers could carry axial bending moment but no twisting moment. This situation could arise toward the end of the test, when the ring was flattened to such

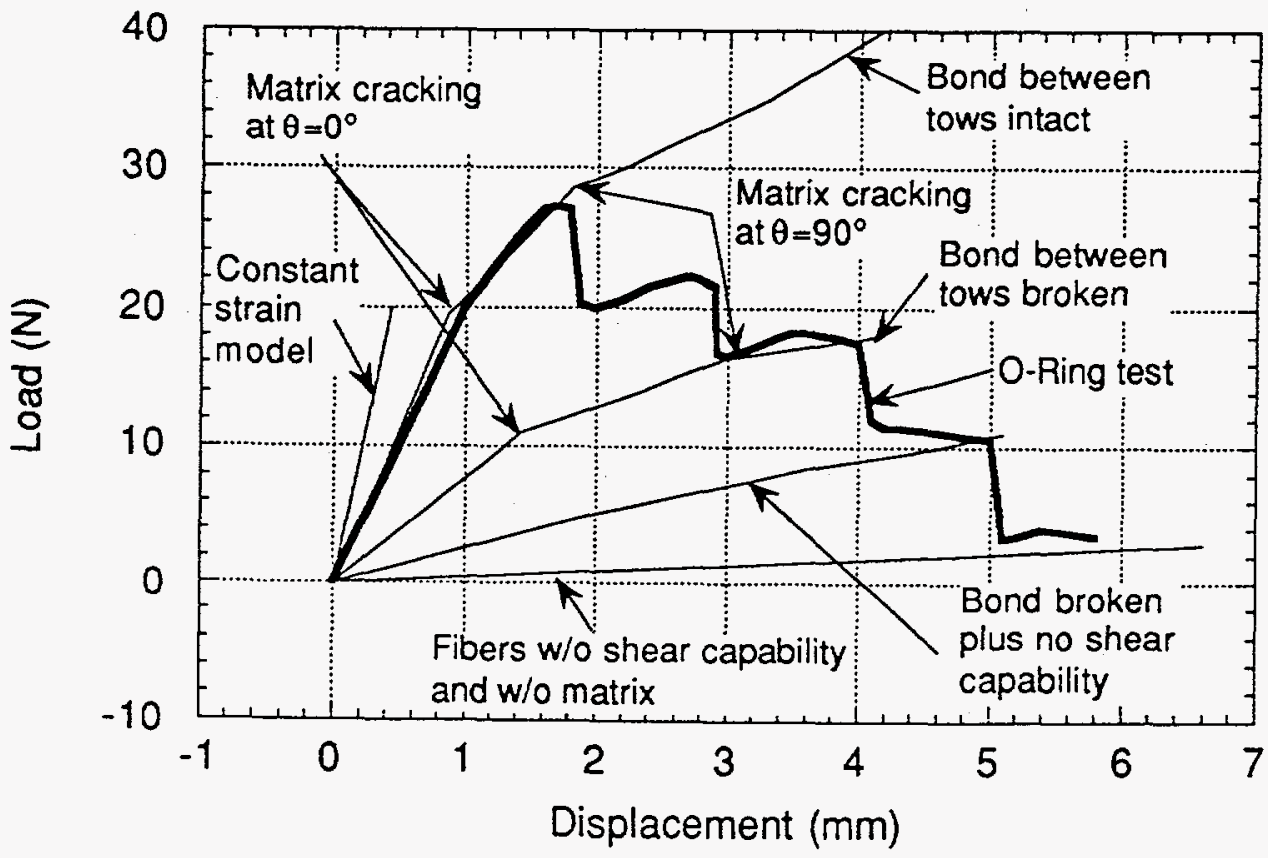

Fig. 18. Predicted vs. observed load-displacement curve for O-ring test on composite cylinder. Constant strain model provided an upper bound. Other predicted curves were based on matrix fracture strength of $170 \mathrm{MPa}$. 


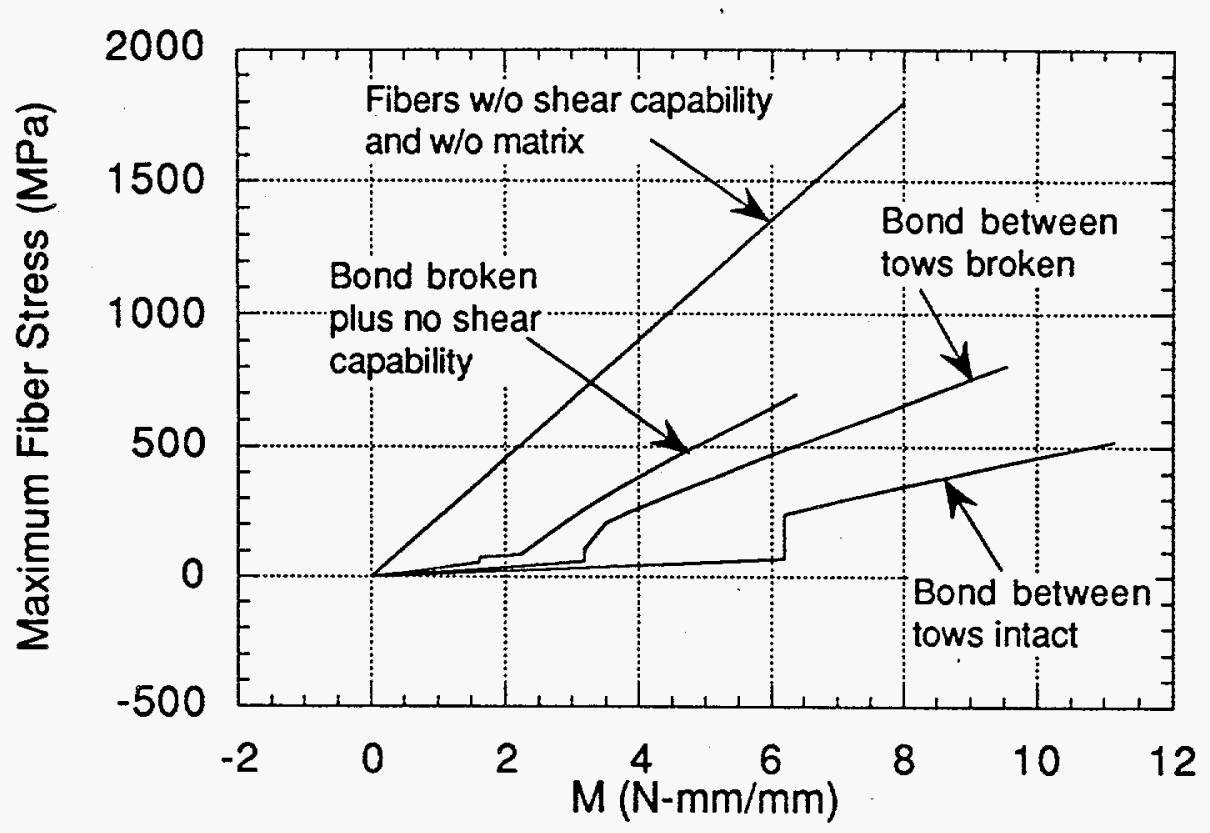

Fig. 19. Variation of maximum fiber stress with bending moment at a section, for various assumptions in model. Highest stress corresponded to when matrix stiffness and shear stiffness of fiber were ignored. Lowest stress occurred when longitudinal shear and interlaminar bonds between tows were intact.

an extent that the top and bottom halves of the ring behaved more and more as flat plates under transverse loading rather than as a circular cylinder. Under such conditions, the cylinder collapsed by the formation of "hinges" under the load $\left(\theta=0^{\circ}\right)$ and at $\theta= \pm 90^{\circ}$ by progressive and possibly unstable cracking of fibers through the thickness.

\subsubsection{O-Ring Bending Test of Composite with a Filter Element}

The maximum load-carrying capability of a composite with the filter element was greater by a factor of nearly 4 than that without the filter element (Fig. 20a). The elastic stiffness was also correspondingly higher. Following the peak load, the load dropped to very low values over a much greater displacement range than in the composite without the filter element. The failure mode for the composite appeared to be dominated by the initiation of a debonded zone under the load point and its subsequent growth along the interface. Analytical modeling of the composite with the filter was somewhat simpler than that for the composite without the filter element because the fiber-reinforced part of the composite could be reasonably assumed to be under membrane loading as long as the bond between the composite and the filter element was unbroken. Details are given in Appendix A.

The calculated variations of the stresses and displacement in the filter as functions of the load are shown in Fig. 21. At a load of $100 \mathrm{~N}$, maximum stresses in the fiber and matrix were significantly below their respective fracture strengths. The stress in the filter element varied from 0 to $-85 \mathrm{MPa}$ (compressive). Calculated displacement of $1.2 \mathrm{~mm}$ was reasonably close to the measured displacement (see Fig. 20a). From the model and visual observations, we concluded that failure was initiated by debonding under the load point at a shear stress of $\approx 3 \mathrm{MPa}$, i.e., debonding initiation strength $\approx 3 \mathrm{MPa}$. 

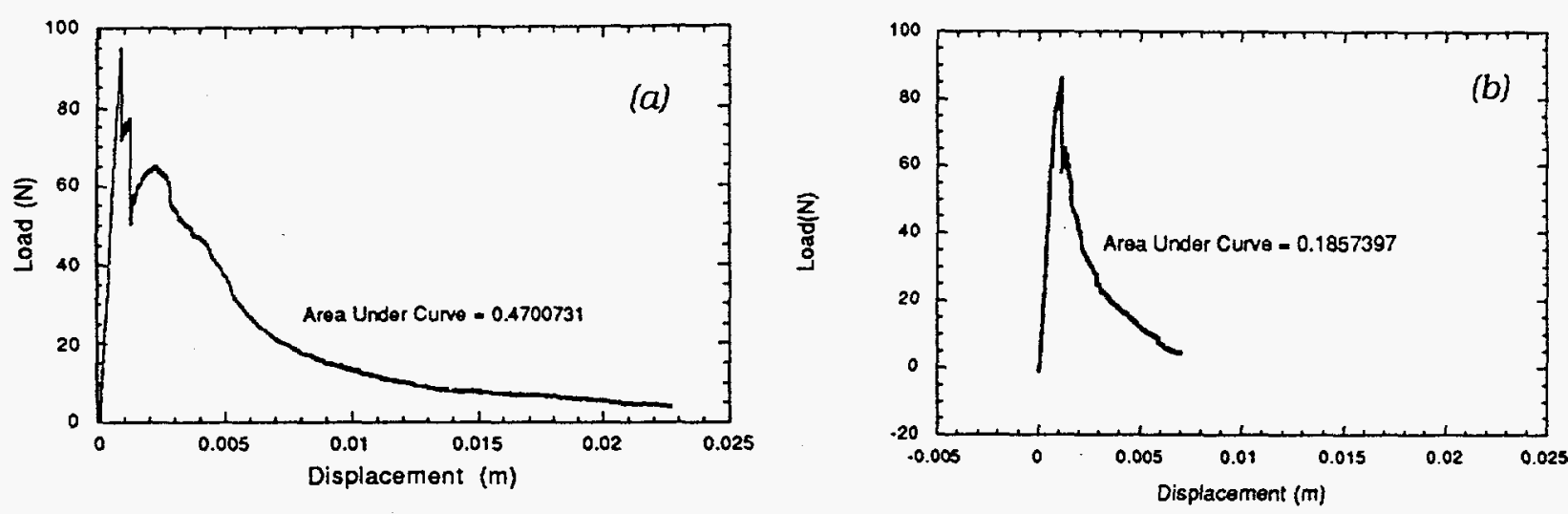

Fig. 20. Typical load-displacement diagram for O-ring bending test on (a) as-received filter and (b) filter subjected to thermal shock quenching temperature of $1100^{\circ} \mathrm{C}$.
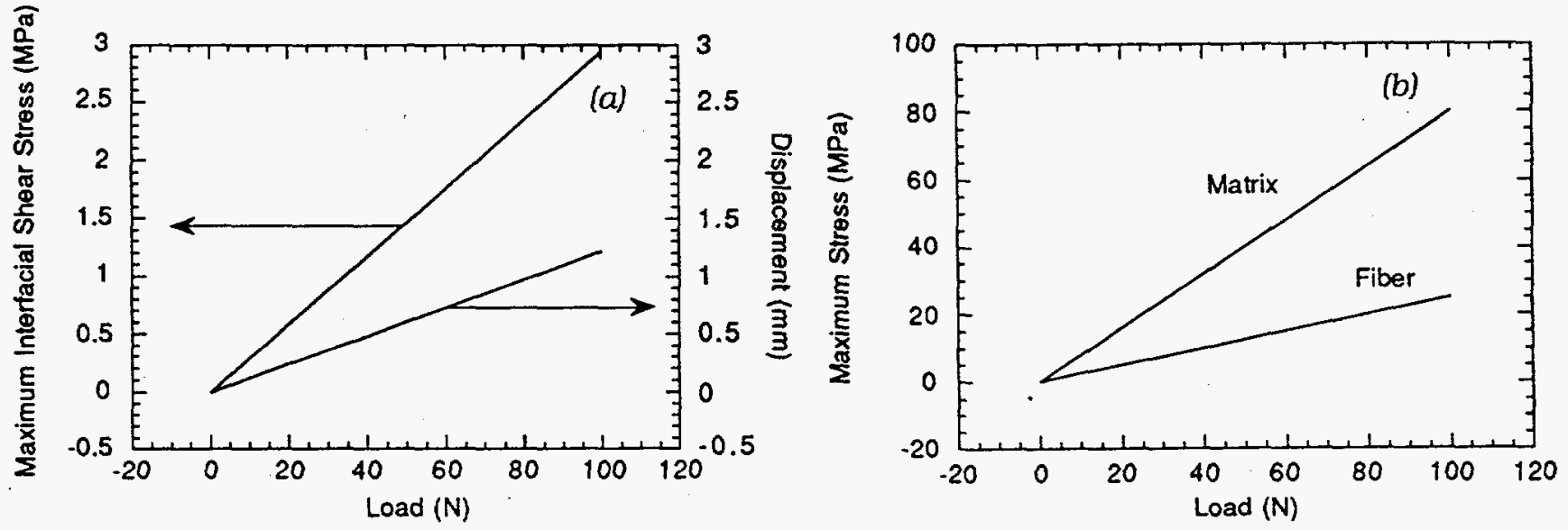

Fig. 21. Calculated variations of (a) displacement and maximum interfacial shear stress and (b) maximum stresses in fiber and matrix with load for composite with filter element.

\subsection{THERMAL-SHOCK EFFECTS}

Following thermal shock, filter specimens were tested by O-ring bending tests. These tests generally showed that the initial slope of the load-displacement curve and the peak fracture load was largely unaffected by thermal shock (Fig. 20b). Although there was a small drop in the peak fracture load for a quenching temperature of $1100^{\circ} \mathrm{C}$, the truly noticeable effect of the thermal shock was on the post-peak-load load-displacement curve. which indicated a more brittle behavior than that for a virgin specimen.

Because the thermal properties of the filter element were not available, a simplified model was used for stress analysis. We assumed conservatively that early in the quenching period, the woven fiber-reinforced composite - because of its open and porous structure rapidly cooled to room temperature. On the other hand, because of resistance to heat flow and insufficient time, the filter element remained at the initial thermal shock maximum temperature. The large difference in temperature caused a tensile membrane stress in 
the composite and compressive membrane stress in the filter element. Because the incompatibility between the thermal expansion coefficients of the fiber and the matrix was small (see Table 1), we assumed that the effective thermal expansion coefficient of each tow in the composite could be estimated by

$$
\alpha_{e f f}=\frac{E_{f} \alpha_{f} v_{f}+E_{m} \alpha_{m} v_{m}}{E_{f} v_{f}+E_{m} v_{m}}
$$

where $\mathrm{E}, \alpha$, and $\mathrm{v}$ are Young's modulus, thermal expansion coefficient, and volume fraction, respectively, with subscripts $f$ and $m$ denoting fiber and matrix, respectively. The problem could then be solved without any information on the thermal properties of the filter element. First, the composite was decoupled from the filter element and the composite was allowed to change its size without significant stress due to cool-down. This caused mismatches in radial and axial dimensions between the composite and the filter element, which were removed by applying appropriate interfacial and axial loads to satisfy equilibrium and compatibility. For a temperature drop of $\Delta \mathrm{T}$, the resulting membrane strains in the composite are given by

$$
\varepsilon_{\mathrm{x}}=\mathrm{K}_{\mathrm{F}}\left(1+\mathrm{v}_{\mathrm{F}}\right) \alpha_{\mathrm{eff}} \Delta \mathrm{T} \frac{\mathrm{K}_{\mathrm{y}}-\mathrm{K}_{\mathrm{xy}}}{\mathrm{K}_{\mathrm{x}} \mathrm{K}_{\mathrm{y}}-\mathrm{K}_{\mathrm{xy}}{ }^{2}}
$$

and

$$
\varepsilon_{y}=K_{F}\left(1+v_{F}\right) \alpha_{e f f} \Delta T \frac{K_{x}-K_{x y}}{K_{x} K_{y}-K_{x y}{ }^{2}},
$$

from which the stresses in the constituents can be calculated. The membrane stresses in the filter element are given by

$$
\sigma_{x}=\frac{E_{F}}{1-v_{F}^{2}}\left[\varepsilon_{x}+v_{F} \varepsilon_{y}-\left(1+v_{F}\right) \alpha_{e f f} \Delta T\right]
$$

and

$$
\sigma_{y}=\frac{E_{F}}{1-v_{F}^{2}}\left[\varepsilon_{y}+v_{F} \varepsilon_{x}-\left(1+v_{F}\right) \alpha_{e f f} \Delta T\right]
$$

Thermal shock did not cause interfacial shear stress except locally at the free edges. Figure 22 shows variations in fiber and matrix stress with quenching temperature. For a fracture strength of $140 \mathrm{MPa}$, the matrix should have cracked at a quenching temperature of $250^{\circ} \mathrm{C}$. Although this might have been a conservative estimate because of the simplifying assumptions of the model, it was balanced because the model ignored the additional stresses in the matrix caused by thermal expansion mismatch with the fibers. The maximum stresses in the fiber were small compared to its fracture strength, even up to a quenching temperature of $1000^{\circ} \mathrm{C}$. Cracking of the matrix was predicted by the model to have very little influence on the initial slope of the load-displacement curve. The maximum interfacial shear stress was also predicted to change little due to matrix cracking. Because the interfacial shear stress was zero (except locally at the free edges) during 


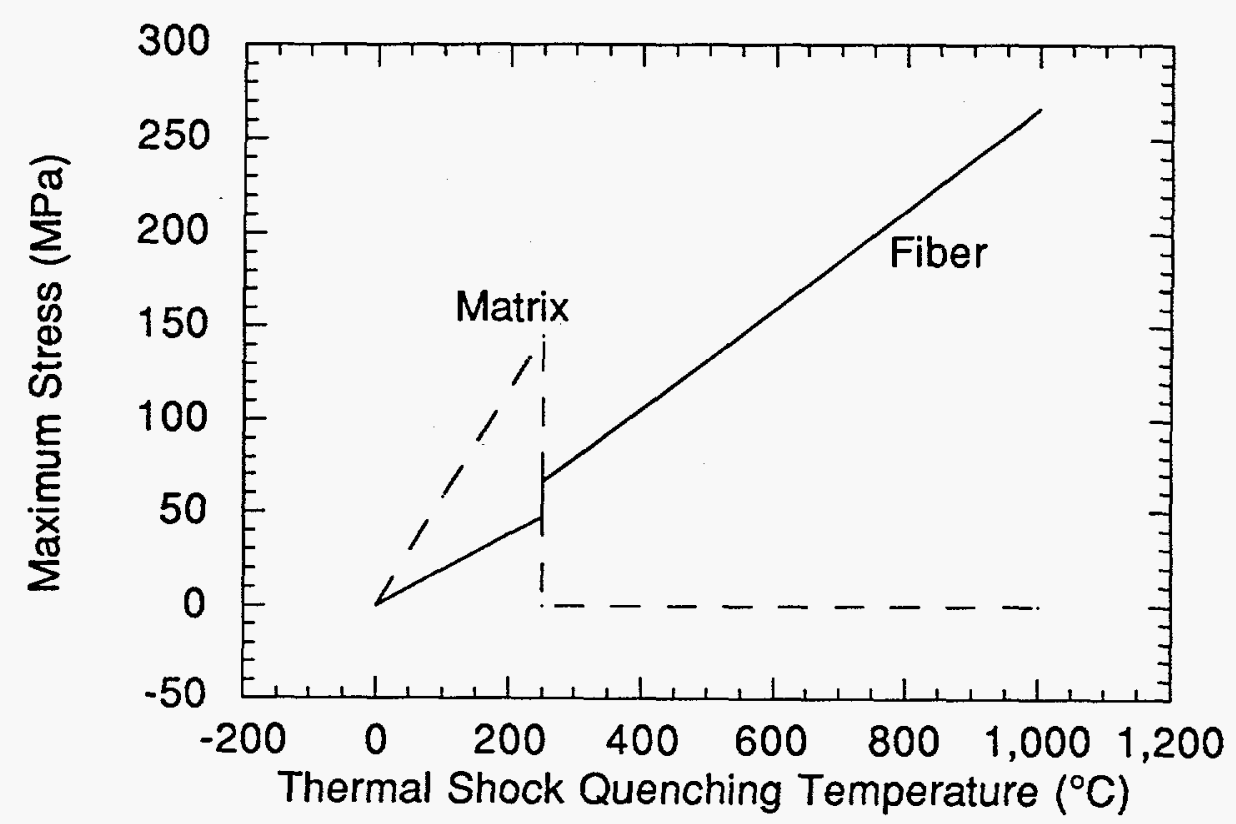

Fig. 22. Variation of maximum stresses in fiber and matrix as functions of quenching temperature for composite with filter element.

thermal shock, the fact that the peak load in an O-ring bend test of a thermally shocked specimen did not change significantly from that of a virgin specimen implied that interfacial shear strength was not affected significantly by the temperature excursion. On the other hand, the drastic changes in the load-displacement curve after the peak load and the brittle fracture surface appearance implied that the fiber/matrix interface was significantly affected by the thermal shock. Matrix microcracking by prior thermal shock may have had an influence on the nature of fiber pull-out during final fracture.

\section{SUMMARY}

We have evaluated the microstructural/mechanical, and thermal shock/fatigue behavior and conducted stress analysis of hot-gas candle filters obtained from different manufacturers. These filters were fabricated from monolithic ceramics and composites. Mechanical property measurement of composite filters included diametral compression testing with O-ring specimens and burst testing of short filter segments with rubber plugs. In general, strengths of composite filters obtained by burst testing were lower than those obtained by O-ring compression testing. Ultimate strength of one of the composite filters exposed in the Tidd demonstration plant for $\approx 1100 \mathrm{hrs}$ decreased by $\approx 60 \%$. This decrease correlates very well with the strength loss of the reinforcing fibers (measured by microscopic technique) and may be related to in-situ fiber damage during filter exposure.

During a single-cycle thermal shock tests, composite filters show little or no strength degradation when quenched from temperatures up to $\approx 900-1000^{\circ} \mathrm{C}$. At higher quenching temperatures, slow strength degradation was observed. Regular monolithic SiC filters were observed to show no strength degradation when quenched from temperatures up to $\approx 700-900^{\circ} \mathrm{C}$, while the strength decreased at a relatively sharper rate at higher temperatures. On the other hand, recrystallized monolithic SiC filter specimens showed higher initial strength and retained this strength to higher quenching temperatures as compared with regular SiC filter specimens. This may be related to the difference in the strength of grain boundary phases in the two cases. For thermal cycles between room temperature 
and $800-1000^{\circ} \mathrm{C}$, composite filters show a small (18-24\%) strength degradation up to three cycles, beyond which strength remained unchanged. Similar behavior with an initial strength drop of $15-28 \%$ was observed for the monolithic filter specimens thermally cycled between room temperature and $800^{\circ} \mathrm{C}$.

Micromechanical models were developed for the 3M filter, both with and without the filter element. Membrane and bending stiffnesses were calculated using the models and mechanical properties of the Nextel ${ }^{\mathrm{TM}}$ fibers and $\mathrm{SiC}$ matrix. Available data on axial tensile tests and O-ring bend tests were predicted reasonably well by the model for the case without the filter element. Since the elastic properties of the filter element were not available, they were estimated by correlation of data with model calculations on O-ring burst tests using an internal plug. Detailed analysis showed that transfer of axial load by friction from the plug to the filter should be negligible. With all the elastic parameters thus determined, the model predicted the initial elastic slopes of the load-displacement curves for the O-ring bend tests quite well and implied that the matrix, fibers, or the filter element should not crack at the experimentally observed peak loads. The sudden drop in the load at peak load could be justified if we assumed, in accordance with experimental observations, that failure was initiated by debonding of the filter element from the rest of the filter. This assumption enabled us to determine experimentally the shear strength of the bond between the filter element and the rest of the woven fiber-reinforced composite.

A conservative model of the thermal shock tests, in which the outside surface of the filter was insulated during the quench, predicted that the matrix of the composite should be microcracked for thermal shock peak temperatures in excess of $250^{\circ} \mathrm{C}$. However such microcracking should not significantly change either the initial slope or the peak load during subsequent $\mathrm{O}$-ring bend tests, as long as the interfacial bond strength between the filter element and the woven fiber-reinforced composite was not adversely affected by the temperature excursion during the thermal shock.

\section{ACKNOWLEDGMENTS}

The work was supported by the U.S. Department of Energy, Office of Fossil Energy, Advanced Research and Technology Materials Program [DOE/FE AA 1510 100, Work Breakdown Structure Element ANL-1A], under Contract W-31-109-Eng-38. The authors thank D. J. Pysher, B. L. Weaver, and R. G. Smith of the 3M Company, J. A. Chambers of Dupont Lanxide Composites, Inc., P. Eggerstedt and J. Zievers of the Industrial Filter \& Pump Manufacturing Company, R. A. Wagner and R. W. Goettler of Babcock \& Wilcox, and John Sawyer of Pall Corporation for providing specimens and for their helpful discussions.

\section{REFERENCES}

1. J. P. Singh, S. Majumdar, A. S. Wagh, T. Wenzel, and R. B. Poeppel, "Materials Qualification Technology for Ceramic Cross-Flow Filters," Argonne National Laboratory Report ANL/FE-91/1 (July 1991).

2. E. A. Ripperger and N. Davis, "Critical Stress in Circular Ring," Trans. Amer. Soc. Civ. Engr., Paper No. 2308, 619-635 (1948).

3. J. P. Singh, D. Singh, and R. A. Lowden, "Effect of Fiber Coating on Mechanical Properties of Nicalon Fibers and Nicalon-Fiber/SiC Matrix Composites," Ceram. Eng. Sci. Proc., Vol. 15 [4], 456-464 (1994).

4. D. Singh and J. P. Singh, "Effect of Processing on Strength of Nicalon Fibers in Nicalon Fiber-SiC Matrix Composites," Ceram. Eng. Sci. Proc., Vol. 13 [7-8], 257-266 (1992).

5. H. P. Kirchner and R. M. Gruver, "Fracture Mirror in Alumina Ceramics," Phil. Mag. 27, 1433-1446 (1973).

6. M.G. Stout and J. J. Petrovic, "Multiaxial Loading Fracture of $\mathrm{Al}_{2} \mathrm{O}_{3}$ Tubes: I, Experiments," J. Am. Ceram. Soc., 67 [1], 14-18 (1984). 


\section{APPENDIX A:}

\section{DETERMINATION OF MEMBRANE AND BENDING STIFFNESSES OF COMPOSITE}

The following geometrical quantities were used to determine various stiffnesses of the composites:

Cross-sectional areas of fibers and matrix in each tow of the first two families were

$$
A_{F l}=\frac{\pi\left(12 \times 10^{-3}\right)^{2}}{4} \times 28 \times 28=0.0887 \mathrm{~mm}^{2}
$$

and

$$
\mathrm{A}_{\mathrm{Ml}}=\left(\frac{1}{2}\right)^{2}-\mathrm{A}_{\mathrm{Fl}}=0.1613 \mathrm{~mm}^{2} .
$$

Thus, the volume fractions of fiber $\left(v_{F 1}\right)$ and matrix $\left(v_{M 1}\right)$ were 0.35 and 0.65 , respectively. The cross-sectional areas for each axial tow were

$$
A_{\mathrm{F} 2}=\frac{\pi\left(10 \times 10^{-3}\right)^{2}}{4} \times 20 \times 20=0.0314 \mathrm{~mm}^{2}
$$

and

$$
A_{M 2}=(0.25)^{2}-A_{F 2}=0.0311 \mathrm{~mm}^{2} .
$$

Thus, the volume fractions of fiber and matrix were 0.5 each in the axial tow. The dimensions of the representative volume element (RVE) in the axial (dx) and circumferential directions (dy) were (Fig. 13)

$$
\mathrm{dx}=5 \mathrm{~mm} \text { and } \mathrm{dy}=10 / \sqrt{ } 3 \mathrm{~mm} \text {. }
$$

The total volumes of fiber and matrix in the RVE were given by

$$
\mathrm{V}_{\mathrm{F}}=\mathrm{V}_{\mathrm{F} 1}+\mathrm{V}_{\mathrm{F} 2}
$$

and

$$
\mathrm{V}_{\mathrm{M}}=\mathrm{V}_{\mathrm{Ml}}+\mathrm{V}_{\mathrm{M} 2}
$$

where

$$
\begin{aligned}
& V_{F 1}=3 \times A_{F 1} \times \frac{10}{\sqrt{3}} \times 2 \times 2=6.1453 \mathrm{~mm}^{3}, \\
& V_{F 2}=A_{F 2} \times 5 \times 2=0.314 \mathrm{~mm}^{3}, \\
& V_{M 1}=3 \times A_{M 1} \times \frac{10}{\sqrt{3}} \times 2 \times 2=11.175 \mathrm{~mm}^{3},
\end{aligned}
$$

and 


$$
\mathrm{V}_{\mathrm{M} 2}=\mathrm{A}_{\mathrm{M} 2} \times 5 \times 2=0.311 \mathrm{~mm}^{3}
$$

The moment of inertia properties of each tow, for an uncracked matrix thickness fraction of $\beta$ (i.e., cracked fraction is $1-\beta$ ), was given by

$$
\mathrm{I}_{\mathrm{M} 1}=\left[\frac{1}{12} \mathrm{x}\left(\frac{1}{2}\right)^{4} \beta^{3}+\beta\left(\frac{1}{2}\right)^{2} z_{\mathrm{o}}^{2}\right] \times \mathrm{v}_{\mathrm{m} 1}=3.361 \times 10^{-3} \beta^{3}+0.16 \beta z_{\mathrm{o}}^{2} \mathrm{~mm}^{4},
$$

where $z_{0}$ was the change in the position of the neutral axis due to cracking,

$$
\begin{aligned}
& \mathrm{I}_{\mathrm{F} 1}=2 \times 28 \times \mathrm{p} \times\left(\frac{12 \times 10^{-3}}{2}\right)^{2}\left(\frac{0.5}{28}\right)^{2} \sum_{\mathrm{i}=1}^{14}(2 \mathrm{i}-1)^{2}=1.845 \times 10^{-3} \mathrm{~mm}^{4} \\
& \mathrm{I}_{\mathrm{F} 2}=2 \times 20 \times \pi \times\left(\frac{10 \times 10^{-3}}{2}\right)^{2}\left(\frac{0.25}{20}\right)^{2} \sum_{i=1}^{10}(2 \mathrm{i}-1)^{2}=1.632 \times 10^{-4} \mathrm{~mm}^{4} \\
& \mathrm{I}_{\mathrm{M} 2}=\frac{1}{12} \times(0.25)^{4}-\mathrm{I}_{\mathrm{F} 2}=1.62 \times 10^{-4} \mathrm{~mm}^{4}
\end{aligned}
$$

The torsional moments of inertia of the three tows depended on the condition of the longitudinal bond between the tows. If the bond was undamaged,

$$
\begin{aligned}
& J_{M 1}=0.263 \times\left(\frac{1}{2}\right)^{4} \times 3 \times \beta^{3} \times v_{M 1}=0.0318 \beta^{3} \mathrm{~mm}^{4} \\
& J_{F 1}=3 \times 2 \times I_{F 1}+2 \times A_{F 1} \times\left(\frac{1}{2}\right)^{2}=0.0558 \mathrm{~mm}^{4}
\end{aligned}
$$

However, if the longitudinal bonds between the three tows of each family were broken, then

$$
\begin{aligned}
& J_{M 1}=3 \times 0.1406 \times\left(\frac{1}{2}\right)^{4} \times \beta^{3} \times v_{M 1}=0.017 \beta^{3} \mathrm{~mm}^{4} \\
& J_{F 1}=3 \times 2 \times I_{F 1}=0.011 \mathrm{~mm}^{4} .
\end{aligned}
$$

\section{MEMBRANE STIFFNESS}

\section{Assumptions}

(1) The bulk of the strain energy due to membrane deformations of each tow was contributed by axial tensile or compressive and in-plane shear deformations. The contributions of transverse tensile, compressive, and shear deformations were negligible.

(2) For computing the membrane stiffnesses, the waviness of the tows was ignored, i.e., tows were assumed to be flat and noninteracting. The stiffness contributions from the 
three families of tows were added linearly. This assumption was reasonable because membrane stiffnesses were linearly related to thicknesses.

(3) Because of the assumed homogeneous stress field in the components of the composite, all of the matrix in a given family of tows was assumed to crack simultaneously in shear or in tension with total loss of shear or tensile-load carrying capability of the matrix while transferring the corresponding load to the fibers. Cracking was simulated by setting the Young's modulus of the matrix material equal to zero.

\section{Composite without Filter Element}

Denoting the axial, circumferential, and transverse coordinates by $\mathrm{x}, \mathrm{y}$, and $\mathrm{z}$, respectively, for applied extensional strains $\varepsilon_{\mathrm{X}}$ and $\varepsilon_{\mathrm{y}}$, the stress resultants were

$$
\begin{aligned}
& N_{x}=K_{x}^{C} \varepsilon_{x}+K_{x y}^{C} \varepsilon_{y} \\
& N_{y}=K_{x y}^{C} \varepsilon_{x}+K_{y}^{C} \varepsilon_{y} .
\end{aligned}
$$

The external work on the RVE was given by

$$
\mathrm{U}=\frac{1}{2}\left[\mathrm{~K}_{\mathrm{x}}^{\mathrm{C}} \varepsilon_{\mathrm{x}}^{2}+2 \mathrm{~K}_{\mathrm{xy}}^{\mathrm{C}} \varepsilon_{\mathrm{x}} \varepsilon_{\mathrm{y}}+\mathrm{K}_{\mathrm{y}}^{\mathrm{C}} \varepsilon_{\mathrm{y}}^{2}\right] \mathrm{dx} \mathrm{dy}
$$

Internally, the axial normal and engineering shear strains in each tow of families 1 and 2 and that of the axial tow were given, respectively, by

$$
\varepsilon_{\mathrm{Al}}=\frac{3}{4} \varepsilon_{\mathrm{x}}+\frac{1}{4} \varepsilon_{\mathrm{y}} \quad \gamma_{\mathrm{Al}}=\frac{\sqrt{3}}{2}\left(\varepsilon_{\mathrm{x}}-\varepsilon_{\mathrm{y}}\right)
$$

and

$$
\varepsilon_{\mathrm{A} 2}=\varepsilon_{\mathrm{X}} \quad \gamma_{\mathrm{A} 2}=0 .
$$

The corresponding axial and in-plane shear loads in each of the tows were

$$
\begin{array}{lc}
\mathrm{N}_{\mathrm{A} 1}=\frac{<\mathrm{EA}_{1}>}{4}\left(3 \varepsilon_{\mathrm{x}}+\varepsilon_{\mathrm{y}}\right), & \mathrm{V}_{\mathrm{A} 1}=<\mathrm{GA}_{1}>\gamma_{\mathrm{Al}}, \\
\mathrm{N}_{\mathrm{A} 2}=<\mathrm{EA}_{2}>\varepsilon_{\mathrm{x}}, \text { and } & \mathrm{V}_{\mathrm{A} 2}=0,
\end{array}
$$

where

$$
\begin{aligned}
& <\mathrm{EA}_{1}>=\mathrm{E}_{\mathrm{M}} \mathrm{A}_{\mathrm{M} 1}+\mathrm{E}_{\mathrm{F}} \mathrm{A}_{\mathrm{F} 1}, \quad\left\langle\mathrm{GA}_{1}>=\alpha\left(\mathrm{G}_{\mathrm{M}} \mathrm{A}_{\mathrm{M} 1}+\mathrm{G}_{\mathrm{F}} \mathrm{A}_{\mathrm{F} 1}\right),\right. \text { and } \\
& <\mathrm{EA}_{2}>=\mathrm{E}_{\mathrm{M}} \mathrm{A}_{\mathrm{M} 2}+\mathrm{E}_{\mathrm{F}} \mathrm{A}_{\mathrm{F} 2},
\end{aligned}
$$

and where $G_{M}$ and $G_{F}$ are the shear moduli of the matrix and fiber and $\alpha$ is assumed equal to 0.1 . The strain energy stored in the RVE was given by 


$$
\mathrm{U}=2 \times\left[3 \mathrm{x} \frac{1}{2}\left(\mathrm{~N}_{\mathrm{A} 1} \varepsilon_{\mathrm{A} 1}+\mathrm{V}_{\mathrm{A} 1} \gamma_{\mathrm{A} 1}\right) \times 2 \mathrm{dy}\right]+\frac{1}{2}\left(\mathrm{~N}_{\mathrm{A} 2} \varepsilon_{\mathrm{A} 2}\right) \times 2 \mathrm{dx}
$$

Substituting for $\mathrm{N}_{\mathrm{A} 1}, \mathrm{~N}_{\mathrm{A} 2}, \varepsilon_{\mathrm{A} 1}$, and $\varepsilon_{\mathrm{A} 2}$ in terms of $\varepsilon_{\mathrm{X}}$ and $\varepsilon_{\mathrm{y}}$, and equating the coefficients of like powers of $\varepsilon_{\mathrm{x}}$ and $\varepsilon_{\mathrm{y}}$ between the two expressions $\mathrm{A} 1$ and $\mathrm{A} 2$,

$$
\begin{aligned}
& \left.\mathrm{K}_{\mathrm{x}}^{\mathrm{C}}=\frac{9}{\mathrm{dx}}\left(\frac{3}{4}<\mathrm{EA}_{1}>+<\mathrm{GA}_{1}\right\rangle\right)+\frac{2}{\mathrm{dy}}\left\langle\mathrm{EA}_{2}>\right. \\
& \mathrm{K}_{\mathrm{y}}^{\mathrm{C}}=\frac{3}{4 \mathrm{dx}}\left(<\mathrm{EA}_{1}>+12<\mathrm{GA}_{1}>\right)
\end{aligned}
$$

and

$$
\mathrm{K}_{\mathrm{xy}}^{\mathrm{C}}=\frac{9}{4 \mathrm{dx}}\left(<\mathrm{EA}_{1}>-4<\mathrm{GA}_{1}>\right)
$$

\section{Composite Plus Filter Element}

Assuming that the filter element is a homogeneous and isotropic solid plate with a membrane stiffness $K_{F}$, the membrane stiffnesses of the full composite were obtained by adding $\mathrm{K}_{\mathrm{F}}$ to the stiffnesses of the composite without the filter, as follows:

$$
\begin{aligned}
& K_{x}=K_{x}^{C}+K_{F} \\
& K_{y}=K_{y}^{C}+K_{F} \\
& K_{x y}=K_{x y}^{C}+v_{F} K_{F},
\end{aligned}
$$

where

$$
K_{F}=\frac{E_{F} h_{F}}{1-v_{F}^{2}}
$$

$h_{F}=$ thickness of filter element $(\approx 1 \mathrm{~mm})$.

and

$E_{F}$ and $v_{F}=$ Young's modulus and Poisson's ratio of filter element. 


\section{BENDING STIFFNESS}

\section{Composite without Filter Element}

\section{Assumptions}

(1) The bulk of the strain energy of the composite due to bending deformations of each tow was contributed by axial bending and twisting deformations. The contributions of transverse bending or twisting deformations were negligible. The twisting rigidity of the three tows in each family depended on the state of the longitudinal shear bond between them.

(2) As long as the interlaminar bond between the three families of tows was undamaged, the waviness of the tows increased the bending stiffness, because it varied approximately as the thickness cubed. For present purposes, this effect was simulated by increasing the tow thicknesses by $20 \%$ and adding the stiffness contributions of the three families of tows linearly as long as the interlaminar bond was unbroken.

(3) As long as the longitudinal bond between the three tows of each of the main families was unbroken, the twisting stiffness corresponded to that of a rectangular section with aspect ratio 3 . If the longitudinal shear bond was broken, then the stiffness was reduced, because it was three times that of a square section.

(4) Progress of cracking in the matrix of a given family of tows for the O-ring bend tests on the composite without the filter element was modeled by assuming a total loss of load-carrying capability of the cracked section of the matrix but retaining full load-carrying capability in the remaining uncracked matrix in the section. In other words, with cracking, the effective thickness of the matrix in a given family of tows was reduced, but the fibers were assumed to remain uncracked and to prevent the matrix cracks from becoming critical.

For applied curvatures of $\mathrm{k}_{\mathrm{x}}$ and $\mathrm{k}_{\mathrm{y}}$, the bending moments were

$$
\begin{aligned}
& M_{x}=D_{x}^{C} \kappa_{x}+D_{x y}^{C} \kappa_{y} \\
& M_{y}=D_{x y}^{C} \kappa_{x}+D_{y}^{C} \kappa_{y},
\end{aligned}
$$

and as before the work done on the RVE was

$$
U=\frac{1}{2}\left(D_{x}^{c} k_{x}^{2}+2 D_{x y}^{c} k_{x} k_{y}+D_{y}^{c} k_{y}^{2}\right) d x d y
$$

Internally, the axial curvature and twist in each tow of families 1 and 2 were

$$
\mathrm{k}_{\mathrm{A} 1}=\frac{3}{4} \mathrm{k}_{\mathrm{x}}+\frac{1}{4} \mathrm{k}_{\mathrm{y}} \text { and } \bar{\omega}_{\mathrm{A} 1}=\left(\mathrm{k}_{\mathrm{x}}-\mathrm{k}_{\mathrm{y}}\right) \frac{\sqrt{3}}{4} \text {. }
$$


The axial curvature and twist in the axial tow was

$$
\mathrm{k}_{\mathrm{A} 2}=\mathrm{k}_{\mathrm{x}} \text { and } \omega_{\mathrm{A} 2}=0 .
$$

The corresponding axial bending and twisting moments in the combined three tows of families 1 and 2 were

$$
\mathrm{M}_{\mathrm{Al}}=\frac{3<\mathrm{EI}_{1}>}{4}\left(3 \kappa_{\mathrm{x}}+\kappa_{\mathrm{y}}\right) \text { and } \mathrm{T}_{\mathrm{Al}}=\frac{\sqrt{3}<\mathrm{GJ}_{1}>}{4}\left(\kappa_{\mathrm{x}}-\kappa_{\mathrm{y}}\right),
$$

where

$$
\left.<\mathrm{EI}_{1}\right\rangle=\mathrm{E}_{\mathrm{F}} \mathrm{IF}_{\mathrm{F}}+\mathrm{E}_{\mathrm{M}} \mathrm{I}_{\mathrm{M} 1} \text { and }\left\langle\mathrm{GJ}_{1}\right\rangle=\mathrm{G}_{\mathrm{F}} \mathrm{F}_{\mathrm{F} 1}+\mathrm{G}_{\mathrm{MJ}} \mathrm{J}_{\mathrm{M}} \text {. }
$$

Axial bending and twisting moments in the axial tow were

$$
\mathrm{M}_{\mathrm{A} 2}=\left\langle\mathrm{EI}_{2}>\mathrm{k}_{\mathrm{X}} \text { and } \mathrm{T}_{\mathrm{A} 2}=0 .\right.
$$

Strain energy stored in the RVE was given by

$$
\mathrm{U}=2 \times\left[\frac{1}{2}\left(\mathrm{M}_{\mathrm{A} 1} \kappa_{\mathrm{Al}}+\mathrm{T}_{\mathrm{A} 1} \Phi_{\mathrm{A} 1}\right) \times 2 \mathrm{dy}\right]+\frac{1}{2}\left(\mathrm{M}_{\mathrm{A} 2} \kappa_{\mathrm{A} 2}\right) \times 2 \mathrm{dx}
$$

Substituting for $N_{\mathrm{A} 1}, N_{\mathrm{A} 2}, \varepsilon_{\mathrm{A} 1}$, and $\varepsilon_{\mathrm{A} 2}$ in terms of $\varepsilon_{\mathrm{x}}$ and $\varepsilon_{\mathrm{y}}$ and equating the coefficients of like powers of $\varepsilon_{\mathrm{X}}$ and $\varepsilon_{\mathrm{y}}$ between the two expressions $\mathrm{A} 4$ and $\mathrm{A} 5$,

$$
\begin{aligned}
& \mathrm{D}_{\mathrm{x}}^{\mathrm{C}}=\frac{3}{4 \mathrm{dx}}\left(9<\mathrm{EI}_{1}>+<\mathrm{GJ}_{1}>\right)+\frac{2}{\mathrm{dy}}<\mathrm{EI}_{2}> \\
& \mathrm{D}_{\mathrm{y}}^{\mathrm{C}}=\frac{3}{4 \mathrm{dx}}\left(<\mathrm{EI}_{1}>+<\mathrm{GJ}_{1}>\right) \\
& \mathrm{D}_{\mathrm{xy}}^{\mathrm{C}}=\frac{3}{4 \mathrm{dx}}\left(3<\mathrm{EI}_{1}>-<\mathrm{GJ}_{1}>\right) .
\end{aligned}
$$

In a typical $\mathrm{O}$-ring bending test, $\mathrm{M}_{\mathrm{X}}=0$, and the bending stiffness for $\mathrm{M}_{\mathrm{y}}$ was given by

$$
D_{y}^{C \prime \prime}=D_{y}^{C}-\frac{D_{x y}^{C}}{D_{x}^{C}} .
$$

\section{Composite plus Filter Element}

\section{Assumptions}

(1) The usual Kirchoff's hypotheses for bending during an O-ring bend test gave linearly varying stresses through the thickness of the filter element. 
(2) The variation of stresses through the thickness of the composite was ignored, i.e., the composite was assumed to respond with membrane stiffnesses $K_{x}^{C}, K_{y}^{C}$, and $K_{x y}^{C}$ acting at a distance yc from the neutral surface.

The satisfaction of zero membrane stress resultants gave the following equation to solve for $\mathrm{y}_{\mathrm{C}}$ :

$$
\mathrm{y}_{\mathrm{C}}{ }^{2}\left(\mathrm{~K}_{\mathrm{x}}^{\mathrm{C}} \mathrm{K}_{\mathrm{y}}^{\mathrm{C}}-\mathrm{K}_{\mathrm{xy}}^{\mathrm{C}}{ }^{2}\right)+\mathrm{y}_{\mathrm{C}} \frac{\mathrm{E}_{\mathrm{F}} \mathrm{y}_{\mathrm{F}} \mathrm{h}_{\mathrm{F}}}{1-\mathrm{v}_{\mathrm{F}}{ }^{2}}\left(\mathrm{~K}_{\mathrm{x}}^{\mathrm{C}}+\mathrm{K}_{\mathrm{y}}^{\mathrm{C}}-2 v_{\mathrm{F}} \mathrm{K}_{\mathrm{xy}}^{\mathrm{C}}\right)+\frac{\left(\mathrm{E}_{\mathrm{F}} \mathrm{y}_{\mathrm{F}} \mathrm{h}_{\mathrm{F}}\right)^{2}}{1-v_{\mathrm{F}}{ }^{2}}=0,
$$

where $y_{F}$ was the distance of the mid-surface of the filter element from the neutral surface of the composite, i.e.,

$$
\mathrm{y}_{F}=\frac{1}{2}\left[2 \mathrm{y}_{F B}+\mathrm{h}_{F}\right]
$$

where $y_{F B}$ was the distance from the neutral surface to the nearest edge of the filter. Initially, $\mathrm{y}_{\mathrm{FB}}$ was assumed $=0$, i.e., the neutral surface was assumed to be at the interface between the filter element and the fiber-reinforced composite.

Integrating the assumed stress distribution through the thickness, the bending moments were expressed as functions of the curvatures as follows:

$$
\begin{aligned}
& M_{x}=D_{x} \kappa_{x}+D_{x y} \kappa_{y} \\
& M_{y}=D_{x y} \kappa_{x}+\dot{D}_{y} \kappa_{y},
\end{aligned}
$$

where

$$
\begin{aligned}
& \mathrm{D}_{\mathrm{x}}=\frac{\mathrm{E}_{\mathrm{F}}}{3\left(1-v_{\mathrm{F}}^{2}\right)}\left[\left(\mathrm{y}_{\mathrm{FB}}+\mathrm{h}_{\mathrm{F}}\right)^{3}-\mathrm{y}_{\mathrm{FB}}{ }^{3}\right]+\mathrm{K}_{\mathrm{x}}^{\mathrm{C} \mathrm{y}_{\mathrm{C}}{ }^{2}} \\
& \mathrm{D}_{\mathrm{y}}=\frac{\mathrm{E}_{\mathrm{F}}}{3\left(1-\mathrm{v}_{\mathrm{F}}^{2}\right)}\left[\left(\mathrm{y}_{\mathrm{FB}}+\mathrm{h}_{\mathrm{F}}\right)^{3}-\mathrm{y}_{\mathrm{FB}}{ }^{3}\right]+\mathrm{K}_{\mathrm{y}}^{\mathrm{C}} \mathrm{y}_{\mathrm{C}}{ }^{2} \\
& \mathrm{D}_{\mathrm{xy}}=\frac{v_{\mathrm{F}} \mathrm{E}_{\mathrm{F}}}{3\left(1-{v_{\mathrm{F}}}^{2}\right)}\left[\left(\mathrm{y}_{\mathrm{FB}}+\mathrm{h}_{\mathrm{F}}\right)^{3}-\mathrm{y}_{\mathrm{FB}}{ }^{3}\right]+\mathrm{K}_{\mathrm{xy}}^{\mathrm{C}} \mathrm{y}_{\mathrm{C}}{ }^{2} .
\end{aligned}
$$

In a typical $O$-ring bending test, $M_{x}=0$, and the bending stiffness for $M_{y}$ was given by

$$
D_{y}^{\prime}=D_{y}-\frac{D_{x y}{ }^{2}}{D_{x}} \text {. }
$$

A critical stress for the composite with the filter element was composite/filterelement interfacial shear stress, which was maximum under the load point. Its value as a function of angular position was given by 
$\tau_{\mathrm{ry}}(\theta)=\frac{1}{R} \frac{d M_{y}}{d \theta} \frac{E_{F}}{D_{y}\left(1-v_{F}^{2}\right)}\left(1-\frac{v_{F} D_{x y}}{D_{x}}\right) \int_{y_{F B}}^{y_{F B}+h_{F}} y d y$.

Because $M_{y}=M-P R \sin \theta$ (see Fig. 11a), and $P=Q /(2 W)$, the above could be integrated, and the maximum shear stress under the load point $(\theta=0)$ could be expressed as

$$
\tau_{r y, \max }=\frac{\Theta}{4 W} \frac{E_{F}}{D_{y}\left(1-v_{F}^{2}\right)}\left(1-\frac{v_{F} D_{x y}}{D_{x}}\right)\left[\left(y_{F B}+h_{F}\right)^{2}-y_{F B}^{2}\right] .
$$




\section{APPENDIX B:}

\section{EFFECTS OF FRICTION ON BURST TESTS WITH INTERNAL PLUG}

Consider the plug test experimental set-up as idealized in Fig. $11 \mathrm{~b}$. Let $\mathrm{R}$ be the radius of the plug and the composite. The problem is symmetrical about $z=0$.

\section{ASSUMPTIONS}

(1) A shear lag analysis was used to model the transfer of axial load from the plug to the composite by friction at the interface.

(2) The contribution of the axial tows, which experience high compressive stresses, to stiffness was ignored.

(3) Cracking of any component was simulated by setting its Young's modulus equal to zero.

\section{EQUILIBRIUM EQUATIONS}

- Global

$\sigma_{x}(x)+\frac{2 N_{x}(x)}{R}=-\frac{P_{A}}{\pi R^{2}}=-p_{A}$,

where $\mathrm{P}_{\mathrm{A}}$ and $\mathrm{PA}_{\mathrm{A}}$ are the applied axial load and pressure on the plug, respectively.

- Plug

$$
\begin{aligned}
& \frac{\mathrm{d} \sigma_{x}(x)}{\mathrm{dx}}=-\frac{2 \tau_{0}(x)}{\mathrm{R}} \\
& \sigma_{r}(r, x)=\sigma_{y}(r, x)=-p(x) \\
& \tau_{r x}(r, x)=\tau_{0}(x) \frac{r}{R},
\end{aligned}
$$

where $\tau_{0}(x)$ and $p(x)$ are the interfacial shear stress and pressure, respectively.

- Composite

$$
\frac{\mathrm{dN}_{\mathrm{x}}(\mathrm{x})}{\mathrm{dx}}=\tau_{\mathrm{o}}(\mathrm{x})
$$

$N_{y}(x)=p(x) R$.

\section{STRESS-STRAIN RELATIONS}

- Plug

$$
\begin{aligned}
& \frac{u_{r}(r, x)}{r}=\varepsilon_{y}(x)=-\frac{1}{E_{R}}\left[\left(1-v_{R}\right) p(x)+v_{R} \sigma_{x}(x)\right] \\
& \frac{\partial u_{x}(0, x)}{\partial x}=\varepsilon_{x}(x)=\frac{1}{E_{R}}\left[\sigma_{x}(x)+2 v_{R} p(x)\right]
\end{aligned}
$$




$$
\gamma_{r x}(r, x)=\frac{\partial u_{x}}{\partial r}+\frac{\partial u_{r}}{\partial x} \cong \frac{\partial u_{x}}{\partial r}=\frac{\tau_{r x}(r, x)}{G_{R}}
$$

where $E_{R}, v_{R}$, and $G_{R}$ are the usual elastic moduli of the plug.

- Composite

$$
\begin{aligned}
& \frac{u_{R}(x)}{R}=\varepsilon_{y}(x)=\frac{N_{y}(x) K_{x}-N_{x}(x) K_{x y}}{K_{x} K_{y}-K_{x y}{ }^{2}} \\
& \frac{d u_{x}(x)}{d x}=\varepsilon_{x}(x)=\frac{N_{x}(x) K_{y}-N_{y}(x) K_{x y}}{K_{x} K_{y}-K_{x y}{ }^{2}},
\end{aligned}
$$

where $K_{x}, K_{y}$, and $K_{x y}$ are the membrane stiffnesses of the composite.

\section{BOUNDARY AND CONTINUITY CONDITIONS}

$$
\begin{aligned}
& \varepsilon_{y}\left(R^{-}, x\right)=\varepsilon_{y}\left(R^{+}, x\right) \\
& 1_{\text {slip }}(x)=u_{x}\left(x, R^{-}\right)-u_{x}\left(x, R^{+}\right)=\left\{\begin{array}{l}
\text { nonzero in slipped region } \\
\text { zero in nonslipped region }
\end{array}\right. \\
& \tau_{0}(x)=\mu p(x) \text { in slipped region } \\
& \sigma_{x}(x)=-p_{A} \text { at } x=L / 2 \\
& \tau_{0}(x)=0 \text { at } x=0 \\
& \sigma_{x}\left(L_{s}^{-}\right)=\sigma_{x}\left(L_{s}^{+}\right) \\
& \tau_{0}\left(L_{s}^{-}\right)=\tau_{0}\left(L_{s}^{+}\right)
\end{aligned}
$$

where $m$ is the friction coefficient and the slipped region extends from $x=L_{S}$ to $x=L / 2$. Eq. B6a, together with Eqs. B4a and B5a, were used to solve for $p(x)$ as follows:

$p(x)=-\beta s_{x}(x)-\alpha p_{A}$.

where

$$
\begin{gathered}
\alpha=\frac{R}{2} \frac{K_{x y}}{R K_{x}+\left(1-v_{R}\right) \frac{D}{E_{R}}} \\
\beta=\alpha+\frac{v_{R} \frac{D}{E_{R}}}{R K_{x}+\left(1-v_{R}\right) \frac{D}{E_{R}}}
\end{gathered}
$$

and

$$
D=K_{x} K_{y}-K_{x y}{ }^{2} .
$$


- Nonslipped region $\left(0<\mathrm{x}<\mathrm{L}_{\mathrm{s}}\right)$

From Eq. B6b,

$u_{\text {slip }}(x)=\frac{d u_{\text {sllp }}(x)}{d x}=0$

Using Eqs. B2c and B4c

$\frac{\partial u_{x}\left(R^{-}, x\right)}{\partial x}=\frac{\partial u_{x}(0, x)}{\partial x}+\frac{R}{2 G_{R}} \frac{d \tau_{0}(x)}{d x}$,

which, on using Eqs. B2a, B4b, and B7a, reduced to

$\frac{\partial u_{x}\left(R^{-}, x\right)}{\partial x}=\frac{1-2 \beta v_{R}}{E_{R}} \sigma_{x}(x)-\frac{2 \alpha v_{R}}{E_{R}} p_{A}-\frac{R^{2}}{4 G_{R}} \frac{d^{2} \sigma_{x}}{d x^{2}}$.

Similarly, using Eqs. B1, B3b and B5b,

$\frac{\partial u_{x}\left(R^{+}, x\right)}{\partial x}=-\frac{R \sigma_{x}(x)}{2 D}\left(K_{y}-2 \beta K_{x y}\right)-\frac{R p_{A}}{2 D}\left(K_{y}-2 \alpha K_{x y}\right)$.

Equating $\mathrm{B} 10 \mathrm{a}$ and $\mathrm{B} 10 \mathrm{~b}$,

$\frac{\mathrm{d}^{2} \sigma_{\mathrm{x}}(\mathrm{x})}{\mathrm{dx}^{2}}-\left(\frac{\gamma_{1}}{\mathrm{R}}\right)^{2} \sigma_{\mathrm{x}}(\mathrm{x})=-\left(\frac{\gamma_{2}}{\mathrm{R}}\right)^{2} \mathrm{p}_{\mathrm{A}}$,

where

$\gamma_{1}^{2}=\frac{4 G_{R}}{E_{R}}\left(1-2 \beta v_{R}\right)+\frac{2 R G_{R}}{D}\left(K_{y}-2 \beta K_{x y}\right)$

and

$\gamma_{2}^{2}=\frac{8 \alpha v_{R} G_{R}}{E_{R}}-\frac{2 R G_{R}}{D}\left(K_{y}-2 \alpha K_{x y}\right)$.

Solving Eq. B1 la,

$\sigma_{x}(x)=B p_{A} \exp \left(\frac{\gamma_{1}}{R} x\right)+C p_{A} \exp \left(-\frac{\gamma_{1}}{R} x\right)+\left(\frac{\gamma_{2}}{\gamma_{1}}\right)^{2} p_{A}$.

Using Eq. B2a,

$\tau_{0}(x)=-\frac{B p_{A} \gamma_{1}}{2} \exp \left(\frac{\gamma_{1}}{R} x\right)+\frac{C p_{A} \gamma_{1}}{2} \exp \left(-\frac{\gamma_{1}}{R} x\right)$

Eqs. B6e and B12b gave

$\mathrm{B}=\mathrm{C}$.

- $\quad$ Slipped region $\left(x>L_{s}\right)$

Using Eqs. B2a, B6c and B7a, 
$\frac{d \sigma_{x}(x)}{d x}=\frac{2 \mu}{R}\left[\beta \sigma_{x}(x)+\alpha p_{A}\right]$

On solving Eq. B14 and using Eq. B6d,

$\sigma_{\mathrm{x}}(\mathrm{x})=-\mathrm{p}_{\mathrm{A}}\left(\frac{\alpha}{\beta}+\left(1-\frac{\alpha}{\beta}\right) \exp \left\{-\left[\frac{2 \beta \mu}{\mathrm{R}}(\mathrm{L} / 2-\mathrm{x})\right]\right\}\right)$

and by Eq. B2a,

$\tau_{0}(\mathrm{x})=\mathrm{p}_{\mathrm{A}} \beta \mu\left(1-\frac{\alpha}{\beta}\right) \exp \left\{-\left[\frac{2 \beta \mu}{\mathrm{R}}(\mathrm{L} / 2-\mathrm{x})\right]\right\}$

Continuity of axial normal and shear stresses at $\mathrm{x}=\mathrm{L}_{\mathrm{s}}$ (Eqs. B6f and B6g) gave

$$
\begin{aligned}
\mathrm{B}\left[\exp \left\{\frac{\gamma_{1} \mathrm{~L}_{\mathrm{s}}}{\mathrm{R}}\right\}+\right. & \left.\exp \left\{-\frac{\gamma_{1} \mathrm{~L}_{\mathrm{s}}}{\mathrm{R}}\right\}\right]+\left(\frac{\gamma_{2}}{\gamma_{1}}\right)^{2}= \\
& \quad\left[\frac{\alpha}{\beta}+\left(1-\frac{\alpha}{\beta}\right) \exp \left(-\left\{\frac{2 \beta \mu}{\mathrm{R}}\left(\mathrm{L} / 2-\mathrm{L}_{\mathrm{s}}\right)\right\}\right)\right]
\end{aligned}
$$

and

$$
\begin{aligned}
-B\left[\exp \left\{\frac{\gamma_{1} L_{s}}{R}\right\}-\exp \left\{-\frac{\gamma_{1} L_{s}}{R}\right\}\right]= & \\
& \beta \mu\left(1-\frac{\alpha}{\beta}\right) \exp \left(-\left\{\frac{2 \beta \mu}{R}\left(L / 2-L_{s}\right)\right\}\right)
\end{aligned}
$$

For a nontrivial solution for Eqs. B16a and $\mathrm{B} 16 \mathrm{~b}$, we must have

$$
\tanh \frac{\gamma_{1} L_{s}}{R}=\frac{\beta \mu\left(1-\frac{\alpha}{\beta}\right) \exp \left(-\left\{\frac{2 \beta \mu}{R}\left(L / 2-L_{s}\right)\right\}\right)}{\frac{\alpha}{\beta}+\left(\frac{\gamma_{2}}{\gamma_{1}}\right)^{2}+\left(1-\frac{\alpha}{\beta}\right) \exp \left(-\left\{\frac{2 \beta \mu}{R}\left(L / 2-L_{s}\right)\right\}\right)}
$$

Note that $L_{s}=0$ (i.e., slippage of the whole plug) could not be a solution unless $m=0$, i.e., a frictionless system. At the other extreme, the whole interface was locked or nonslipping if $\mathrm{L}_{\mathrm{S}}=\mathrm{L} / 2$, which implied (from Eq. B17) the following critical friction coefficient:

$$
\mu_{\mathrm{cr}}=\frac{1+\left(\frac{\gamma_{2}}{\gamma_{1}}\right)^{2}}{\beta-\alpha} \tanh \frac{\gamma_{1} \mathrm{~L}}{2 \mathrm{R}} .
$$

\section{Case 1}

If $\mu<\mu_{\mathrm{cr}}$, a part of the interface from $\mathrm{x}=0$ to $\mathrm{x}=\mathrm{L}_{\mathrm{s}}$ was non-slipping and the rest of the interface from $x=L_{s}$ to $x=L / 2$ was sliding. In this case, after solving for $L_{s}$ from Eq. A17, B was evaluated from Eq. B16b: 
$B=-\frac{\beta \mu\left(1-\frac{\alpha}{\beta}\right) \exp \left(-\left\{\frac{2 \beta \mu}{R}\left(L / 2-L_{s}\right)\right\}\right)}{\left[\exp \left\{\frac{\gamma_{1} L_{s}}{R}\right\}-\exp \left\{-\frac{\gamma_{1} L_{s}}{R}\right\}\right]}$.

The end displacement of the plug was obtained from Eqs. B4b and B7a:

$u_{x, \max }=\frac{1-2 \beta v_{R}}{E_{R}} \int_{0}^{L / 2} \sigma_{x} d x-\frac{\alpha v_{R}}{E_{R}} L p_{A}$,

which was evaluated from Eqs. B12a and B15a as follows:

$$
\begin{aligned}
\frac{\mathrm{u}_{\mathrm{x}, \max }}{\mathrm{p}_{\mathrm{A}}} & =\frac{1-2 \beta v_{\mathrm{R}}}{\mathrm{E}_{\mathrm{R}}}\left(\frac{2 \mathrm{BR}}{\gamma_{1}} \sinh \left(\frac{\gamma_{1} \mathrm{~L}_{\mathrm{s}}}{\mathrm{R}}\right)+\left(\frac{\gamma_{2}}{\gamma_{1}}\right)^{2} \mathrm{~L}_{\mathrm{s}}-\frac{\alpha}{\beta}\left(\frac{\mathrm{L}}{2}-\mathrm{L}_{\mathrm{s}}\right)\right. \\
& \left.-\frac{\mathrm{R}}{2 \beta \mu}\left(1-\frac{\alpha}{\beta}\right)\left\{1-\exp \left[-\frac{2 \beta \mu}{\mathrm{R}}\left(\mathrm{L} / 2-\mathrm{L}_{\mathrm{s}}\right)\right]\right\}\right)-\frac{\alpha v_{\mathrm{R}}}{\mathrm{E}_{\mathrm{R}}} \mathrm{L}
\end{aligned}
$$

\section{Case 2}

If $\mu \geq \mu_{\mathrm{cr}}$, the whole interface was nonslipping and the constant $\mathrm{B}$ was determined from Eq. B12a by the boundary condition B6d,

$$
\mathrm{B}=-\frac{1+\left(\frac{\gamma_{2}}{\gamma_{1}}\right)^{2}}{2 \cosh \left(\frac{\gamma_{1} \mathrm{~L}}{2 \mathrm{R}}\right)},
$$

and the maximum end displacement was given by

$$
\frac{u_{x, \max }}{p_{A}}=\frac{1-2 \beta v_{R}}{E_{R}}\left[\frac{2 B R}{\gamma_{1}} \sinh \left(\frac{\gamma_{1} L}{2 R}\right)+\left(\frac{\gamma_{2}}{\gamma_{1}}\right)^{2} \frac{L}{2}\right]-\frac{\alpha v_{R}}{E_{R}} L \text {. }
$$

A typical test setup is shown in Fig. 11b. Lengths of the filter and the plug were $25.4 \mathrm{~mm}$ ( 1 in.) and $38.1 \mathrm{~mm}$ (1.5 in.), respectively. We assumed that all components were uncracked at the beginning of the test. For the initial model calculations, we assumed that the plug had the same length as the composite without the filter element. The cases involving a filter element and a longer plug length are discussed in the main section.

The variations of the axial and hoop stress resultants in the composite (without the filter element) per unit applied axial load on the plug are plotted in Fig. Bla. The results clearly showed that the hoop stress resultants dominated the axial stress resultants in the composite for all values of friction coefficient. Figure Blb shows that the slope of the loaddisplacement curve was not changed significantly by friction. Therefore, it was reasonable to ignore all friction effects in the analysis of the filter. 


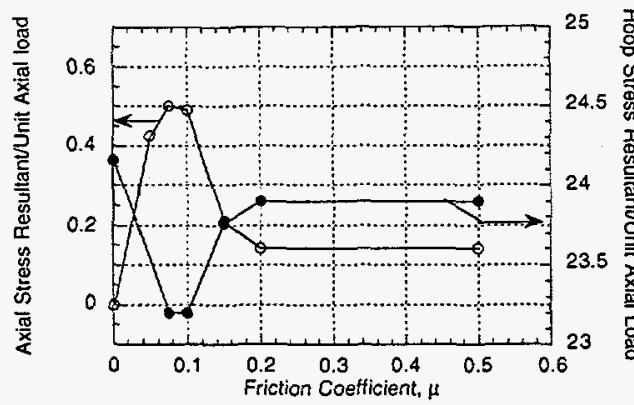

(a)

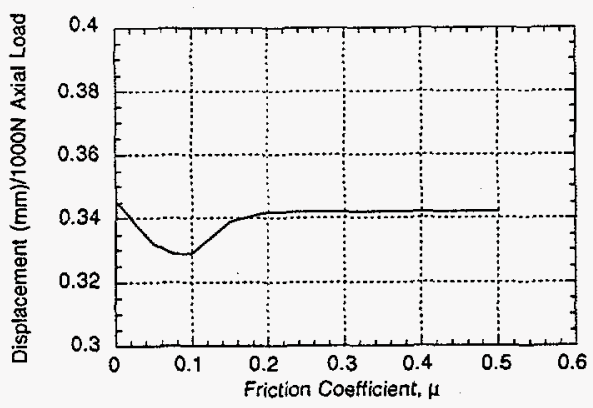

(b)

Fig. B1. Effects of friction coefficient on (a) axial and hoop stress resultants (MPa-mm) in composite per unit applied axial load (N), and (b) initial elastic slope of plug load-displacement diagram for composite without filter element. 


\section{Distribution for ANL-FE/97-01}

Internal:

U. Balachandran

C. Malefyt

M. Sutaria

H. Drucker

K. Natesan

R. A. Valentin

W. A. Ellingson

R. B. Poeppel

R. W. Weeks

S. P. Henslee (ANL-W)

D. K. Schmalzer

ANL Contract File

S. H. D. Lee

W. J. Shack

S. Majumdar

J. P. Singh (10)

ANL Patent Department

TIS Files

External:

ANL-E Library

ANL-W Library

Manager, Chicago Field Office, DOE

OSTI ( 2 copies)

Energy Technology Division Review Committee:

H. K. Birnbaum, University of Illinois at Urbana-Champaign, Urbana

R. C. Buchanan, University of Cincinnati, Cincinnati, $\mathrm{OH}$

S.-N. Liu, Fremont, CA

H. S. Rosenbaum, Fremont, CA

R. K. Shah, University of Kentucky, Lexington

S. Smialowska, Ohio State University, Columbus

R. E. Smith, Altran Corp., Huntersville, NC

U. S. Department of Energy. Washington:

Office of Basic Energy Sciences:

H. M. Kerch

Office of Fossil Energy:

F. M. Glaser

Office of Vehicle and Energy R\&D:

R. B. Schulz

DOE Idaho Operations Office:

J. B. Malmo

DOE Federal Energy Technology Center - Morgantown:
R. Bedick
N. T. Holcombe
D. C. Cicero
W. J. Huber
F. W. Crouse, Jr.
T. J. McMahon
R. A. Dennis
J. E. Notestein

DOE Federal Energy Technology Center - Pittsburgh:
A. L. Baldwin
L. A. Ruth
G. V. McGurl
T. M. Torkos

DOE Oak Ridge Operations:

Asst. Mgr. for Energy Research and Development

M. H. Rawlins 
Oak Ridge National Laboratory:

P. T. Carlson D. P. Stinton

F. D. Johnson (5) M. R. Upton

R. R. Judkins

Other Government - University - Industry:

M. A. Alvin, Westinghouse Electric Corporation, Pittsburgh

H. Atwell, Dow Corning Corporation, Midland, MI

W. T. Bakker, Electric Power Research Institute, Palo Alto, CA

R. J. Buss, Sandia National Laboratories

G. A. Carlson, Sandia National Laboratories

J. A. Chambers, DuPont Lanxide, Newark, DE

H. Cheung, Union Carbide Corporation, Tonawanda, NY

W. J. Chmura, The Torrington Company, Torrington, CT

N. Corbin, The Norton Company, Northborough, MA

T. B. Cox, AMA Research \& Development Center, Golden, CO

W. A. Curtin, Virginia Polytechnic Institute \& State University, Blacksburg

S. W. Dean, Air Products and Chemicals, Allentown, PA

P. Eggerstedt, Industrial Filter and Pump Mfg., Cicero, IL

S. G. Fishman, Office of Naval Research, Arlington, VA

W. C. Fort, Shell Development Company, Houston

M. Gold, Babcock \& Wilcox, Barberton, $\mathrm{OH}$

R. S. Gordon, Virginia Polytechnic Institute and State University, Blacksburg

R. W. Goettler, Babcock \& Wilcox, Barberton, $\mathrm{OH}$

R. E. Green, Jr., The Johns Hopkins University, Baltimore

T. D. Gulden, GA Technologies, Inc., San Diego, CA

D. P. H. Hasselman, Virginia Polytechnic Institute and State University, Blacksburg

C. M. Huang, Tennessee Valley Authority, Chattanooga, TN

J. D. Katz, Los Alamos National Laboratory

D. J. Kenton, EC Technologies, San Antonio, TX

P. Khandelwal, Allison Gas Turbine Division, Indianapolis

P. Liaw, University of Tennessee, Knoxville

M. A. Leitheiser, 3M Company, St. Paul, MN

T. Lippert, Westinghouse Electric Corp., Pittsburgh

T. Mulholland, Lava Crucible-Refractories Company, Zelienople, PA

J. Oakey, British Coal Corp., Gloucestershire, England, U.K.

M. Prager, The Materials Properties Council, Inc., New York

K. M. Prewo, United Technologies Research Center, East Hartford, CT

D. J. Pysher, 3M Company, St. Paul, MN

B. H. Rabin, Idaho National Engineering and Environmental Laboratory

K. L. Reifsnider, Virginia Polytechnic Institute \& State University, Blacksburg

R. W. Revic, Canada Center for Mineral \& Energy Technology, Ottawa, Ontario

M. Sahoo, Canada Center for Mineral \& Energy Technology, Ottawa, Ontario

A. G. Sault, Sandia National Laboratories

J. Sawyer, Pall Corp., Cortland, NY

V. K. Sethi, Western Research Institute, Laramie, WY

S. G. Singhal, Westinghouse Electric Corp., Pittsburgh

R. G. Smith, 3M Company, St. Paul, MN

T. L. Starr, Georgia Institute of Technology, Atlanta

W. A. Steele, Lawrence Livermore National Laboratory

T. G. Stoebe, University of Washington, Seattle

J. Stringer, Electric Power Research Institute, Palo Alto, CA

M. Van de Voorde, European Communities Joint Research Center, Petten, The Netherlands 
R. A. Wagner, Babcock \& Wilcox, Lynchburg, VA

B. L. Weaver, 3M Company, St. Paul, MN

R. A. Wenglarz, Allison Gas Turbine Division, Indianapolis

J. Zievers, Industrial Filter \& Pump Mfg., Cicero, IL

K. M. Zwilsky, National Matls. Advisory Board, National Research Council, Washington, DC 